\title{
Polymer Networks Synthesized from Poly(Sorbitol Adipate) and Functionalized Poly(Ethylene Glycol)
}

\author{
Haroon Rashid ${ }^{1,2}$, Yury Golitsyn ${ }^{3}{ }^{(0)}$, Muhammad Humayun Bilal $\left.{ }^{1}{ }^{(}\right)$, Karsten Mäder ${ }^{2}{ }^{(D}$, Detlef Reichert $^{3}$ and \\ Jörg Kressler 1,*(D) \\ 1 Department of Chemistry, Martin Luther University Halle-Wittenberg, D-06120 Halle (Saale), Germany; \\ haroon.rashid@student.uni-halle.de (H.R.); muhammad.bilal@chemie.uni-halle.de (M.H.B.) \\ 2 Institute of Pharmacy, Martin Luther University Halle-Wittenberg, D-06120 Halle (Saale), Germany; \\ karsten.maeder@pharmazie.uni-halle.de \\ 3 Department of Physics, Martin Luther University Halle-Wittenberg, D-06120 Halle (Saale), Germany; \\ yury.golitsyn@physik.uni-halle.de (Y.G.); detlef.reichert@physik.uni-halle.de (D.R.) \\ * Correspondence: joerg.kressler@chemie.uni-halle.de; Tel.: +49-345-552-5800
}

Citation: Rashid, H.; Golitsyn, Y.; Bilal, M.H.; Mäder, K.; Reichert, D.; Kressler, J. Polymer Networks Synthesized from Poly(Sorbitol Adipate) and Functionalized Poly(Ethylene Glycol). Gels 2021, 7, 22. https://doi.org/ 10.3390/gels7010022

Received: 29 January 2021

Accepted: 13 February 2021

Published: 20 February 2021

Publisher's Note: MDPI stays neutral with regard to jurisdictional claims in published maps and institutional affiliations.

Copyright: (c) 2021 by the authors. Licensee MDPI, Basel, Switzerland. This article is an open access article distributed under the terms and conditions of the Creative Commons Attribution (CC BY) license (https:// creativecommons.org/licenses/by/ $4.0 /)$.

\begin{abstract}
Polymer networks were prepared by Steglich esterification using poly(sorbitol adipate) (PSA) and poly(sorbitol adipate)-graft-poly(ethylene glycol) mono methyl ether (PSA-g-mPEG ${ }_{12}$ ) copolymer. Utilizing multi-hydroxyl functionalities of PSA, poly(ethylene glycol) (PEG) was first grafted onto a PSA backbone. Then the cross-linking of PSA or PSA-g-mPEG 12 was carried out with disuccinyl PEG of different molar masses (Suc-PEG ${ }_{n}-$ Suc). Polymers were characterized through nuclear magnetic resonance (NMR) spectroscopy, gel permeation chromatography (GPC), and differential scanning calorimetry (DSC). The degree of swelling of networks was investigated through water $\left(\mathrm{D}_{2} \mathrm{O}\right)$ uptake studies, while for detailed examination of their structural dynamics, networks were studied using ${ }^{13} \mathrm{C}$ magic angle spinning NMR $\left({ }^{13} \mathrm{C}\right.$ MAS NMR) spectroscopy, ${ }^{1} \mathrm{H}$ double quantum NMR ( ${ }^{1} \mathrm{H}$ DQ NMR) spectroscopy, and ${ }^{1} \mathrm{H}$ pulsed field gradient NMR $\left({ }^{1} \mathrm{H}\right.$ PFG NMR) spectroscopy. These solid state NMR results revealed that the networks were composed of a two component structure, having different dipolar coupling constants. The diffusion of solvent molecules depended on the degree of swelling that was imparted to the network by the varying chain length of the PEG based cross-linking agent.
\end{abstract}

Keywords: networks; hydrogel; crosslinking; enzymatic synthesis; sugar alcohol; functional polyester; Steglich esterification; poly(sorbitol adipate); PEG; solid-state NMR

\section{Introduction}

Polymer networks are three-dimensional cross-linked structures being applied in various fields, ranging from rubber [1,2] and food industry [3], to bio-medical [4] and pharmaceutical industry [5]. Such polymer architectures are held together by cross-links or junctions, which are formed by strong physical interactions or covalent bonds [6]. The obtained materials possess special properties, such as high elasticity, porosity, swellability etc., which can be modulated to the desired properties of the intended application [3]. Hydrogels or hydrophilic polymer networks are especially well-known for their biomedical applications, because of similar mechanical properties to natural tissues and cells [5,7-9].

Networks can be synthesized and modulated according to various factors, like biocompatibility, mechanical strength, hydrophilicity, hydrophobicity, etc. [10,11]. Aliphatic polyesters belong to a class of polymers that have been extensively studied as precursors for the formation of networks, especially for biomedical applications [12-14]. Unfortunately, they usually possess a strong hydrophobic character and lack pendant functional groups for conjugation with polymers and biologically active species such as proteins, drugs, or antibodies, etc. $[14,15]$. Thus, the absence of pendant functional groups along the 
polymer backbone restricts the modulation for desired material properties $[11,16]$. Alternatively, enzymatic polymerization can be used for the synthesis of functional polyesters with different advantages $[17,18]$. It has emerged as a versatile technique for green polymer synthesis over more than two decades, and where enzymes work as biocatalysts to drive the chemical reaction [19-22]. Thus, it avoids the risk of toxicity which can occur due to metal based catalysts (zinc, aluminum, tin, antimony etc.), used in conventional polycondensation procedures for the production of aliphatic polyesters [22]. Enzymes also render the regioselectivity to the polymerization mechanism under mild reaction conditions producing linear polymers with a low degree of branching, even when multiple $\mathrm{OH}$-group (>2) bearing monomers are employed, such as glycerol or different sugars [23]. It thus can form highly efficient polyesters with pendant functionalities, and avoiding the protection/deprotection chemistry which generally is utilized to functionalize conventional aliphatic polyesters $[20,24-26]$. These polyesters have been utilized in developing different drug delivery carriers, like nanoparticulate systems (nanospheres, nanocubes) [27-30], micelles [31], microparticles [32], and polymer drug conjugates [29,33,34].

Here, we employed enzymatically synthesized poly(sorbitol adipate) (PSA). Every sorbitol part of the linear polyester repeat-unit has four pendant secondary $\mathrm{OH}$-groups, which render the polyester hydrophilic [35]. In order to increase the hydrophilicity of PSA and later the swellability of the networks, some poly(ethylene glycol) (PEG) sidechains were grafted. Finally, using bifunctional PEG with different molar masses, networks with different application profiles were produced and extensively characterized. Various solid-state NMR techniques were employed to characterize the dynamics of the hydrogels swollen in $\mathrm{D}_{2} \mathrm{O}$.

\section{Results and Discussion}

\subsection{Polymer Syntheses}

Poly(sorbitol adipate) (PSA) was synthesized through lipase CAL-B catalyzed polycondensation reaction using the sugar alcohol sorbitol and divinyl adipate. The selection of divinyl esters was preferred over dicarboxylic acids or dialkyl esters because the latter result in reaction by-products like water, methanol, etc. which require vacuum and high temperatures in order to be removed from the reaction mixture [36]. Another reason to select divinyl adipate was connected with the fact that relatively high molar mass polyesters are obtained. Here, the byproduct vinyl alcohol, which tautomerizes spontaneously to acetaldehyde, leaves the reaction as a gas. This process drives the reaction irreversibly in a forward direction [37-39]. The sugar alcohol sorbitol was selected since the two primary $\mathrm{OH}$-groups are converted during the polycondensation process, but four secondary $\mathrm{OH}$ groups per repeat unit of the polyester remain free, which guarantee the water solubility of PSA [40]. Hence, a linear polyester is achieved due to the selectivity of CAL-B towards primary hydroxyl groups rather than secondary ones [41]. The PSA structure was confirmed from ${ }^{1} \mathrm{H}$ NMR, ${ }^{13} \mathrm{C}$ NMR, and ${ }^{13} \mathrm{C}$ MAS NMR spectra given in Figure 1a, Figure S1 (Supplementary Materials), and Figure S2 (Supplementary Materials), respectively. 


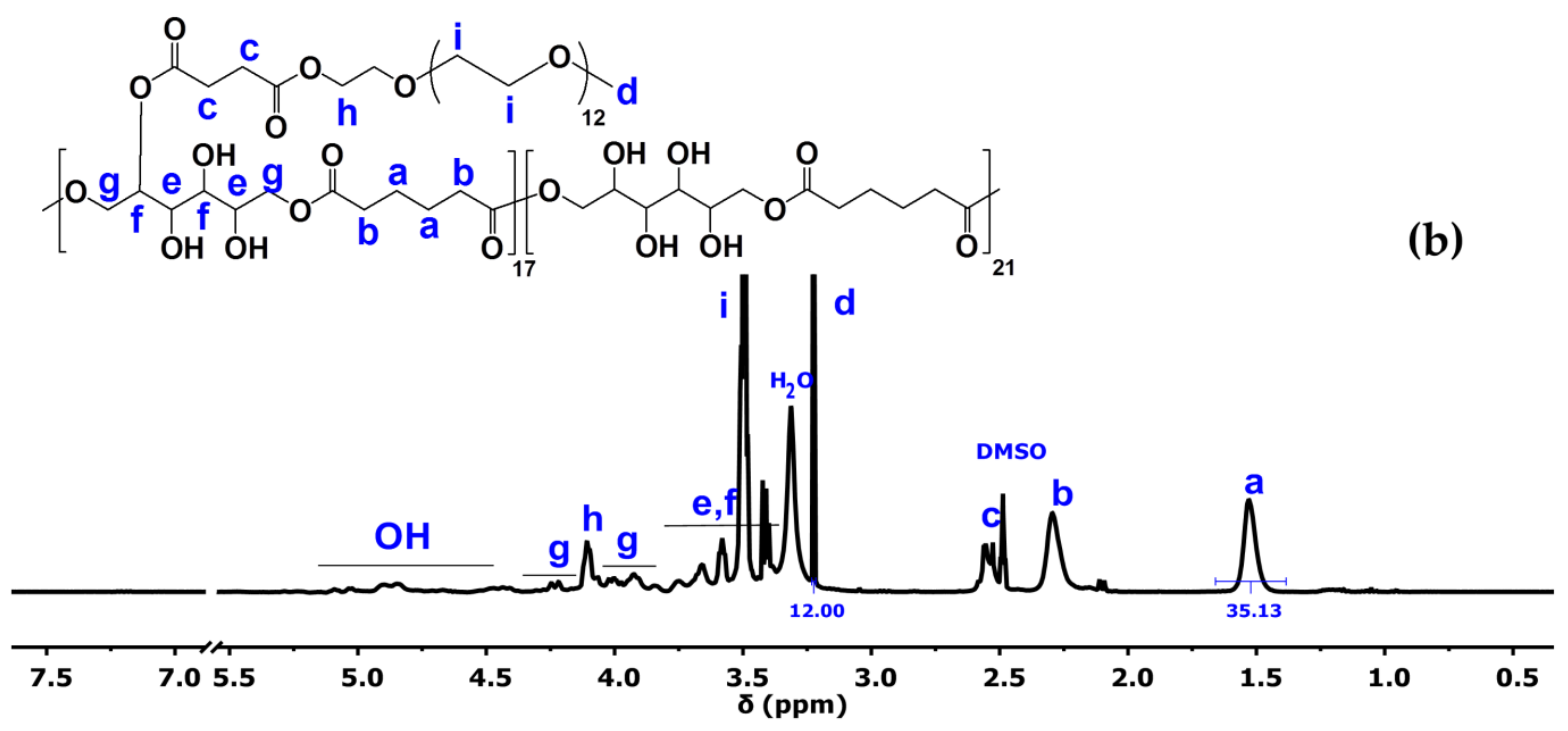

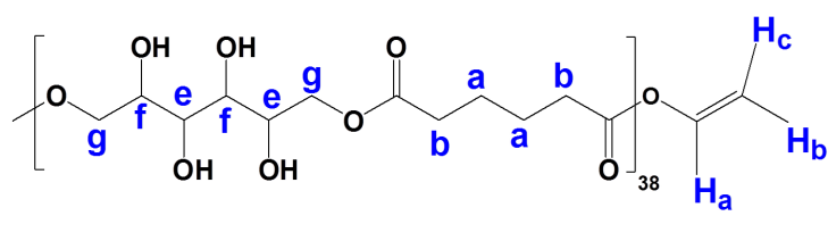

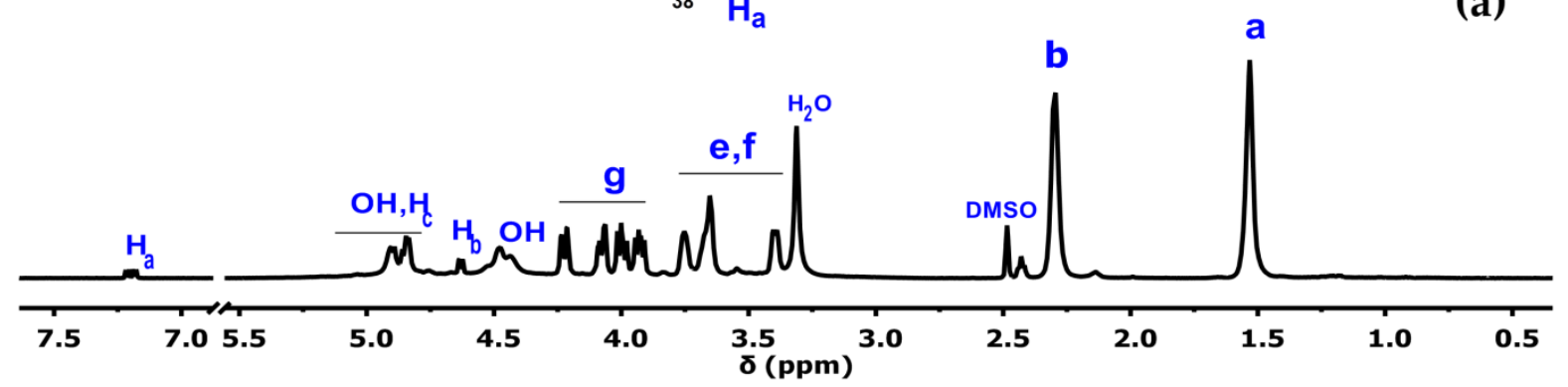

Figure 1. ${ }^{1} \mathrm{H}$ NMR spectra of (a) PSA (poly(sorbitol adipate)) and (b) PSA-g-mPEG 12 measured at $27^{\circ} \mathrm{C}$ using DMSO-d 6 as solvent.

Our objective was to synthesize biocompatible PSA networks which could be used as hydrogel for potential applications in pharmacy and medicine. For this purpose, PSA was first modified by grafting with PEG chains. This further improves the hydrophilicity of the polymer. PEG is known as a versatile biocompatible polymer with a well-recognized safety profile. For these reasons, it has been in use for decades for different purposes in the pharmaceutical industry [42]. To achieve the grafting reaction, $\mathrm{mPEG}_{12}-\mathrm{OH}$ was first reacted with succinic anhydride in the presence of 4-(dimethylamino)pyridine (DMAP) to obtain the monofunctional $\alpha$-methoxy, $\omega$-succinyl poly(ethylene glycol) ( $\left.\mathrm{mPEG}_{12}-\mathrm{Suc}\right)$ (Scheme S1, Supplementary Materials). The reaction was verified by ${ }^{1} \mathrm{H}$ NMR spectroscopy (Figure S3, Supplementary Materials).

To synthesize PSA-g-mPEG 12 , Steglich esterification was adopted for the grafting procedure via the reaction between free hydroxyl groups from PSA and carboxyl groups from $\mathrm{mPEG}_{12}$-Suc. The synthesis of PSA- $g-\mathrm{mPEG}_{12}$ could be confirmed from ${ }^{1} \mathrm{H} \mathrm{NMR}$ (Figure $1 \mathrm{~b}$ ) and ${ }^{13} \mathrm{C}$ NMR spectra (Figure 2). The appearance of the methyl peak at $3.23 \mathrm{ppm}$ and methylene peak at 3.50 ppm of PEG in the ${ }^{1} \mathrm{H}$ NMR spectrum, while in the ${ }^{13} \mathrm{C}$ NMR spectrum, the carbon signal of the methyl group at $58.10 \mathrm{ppm}$ and the carbon signal of the methylene group at 69.85 ppm of PEG, verified the grafting of the $\mathrm{mPEG}_{12}$ chain to PSA. Equation (1) was employed for the calculation of the degree of grafting in $\mathrm{mol} \%$.

$$
\text { Degree of grafting }=\frac{1 / 3 \int d}{1 / 4 \int a} \times 100
$$


where $d$ represents the protons of the methyl group of PEG, and $a$ represents the protons of the methylene groups of PSA.

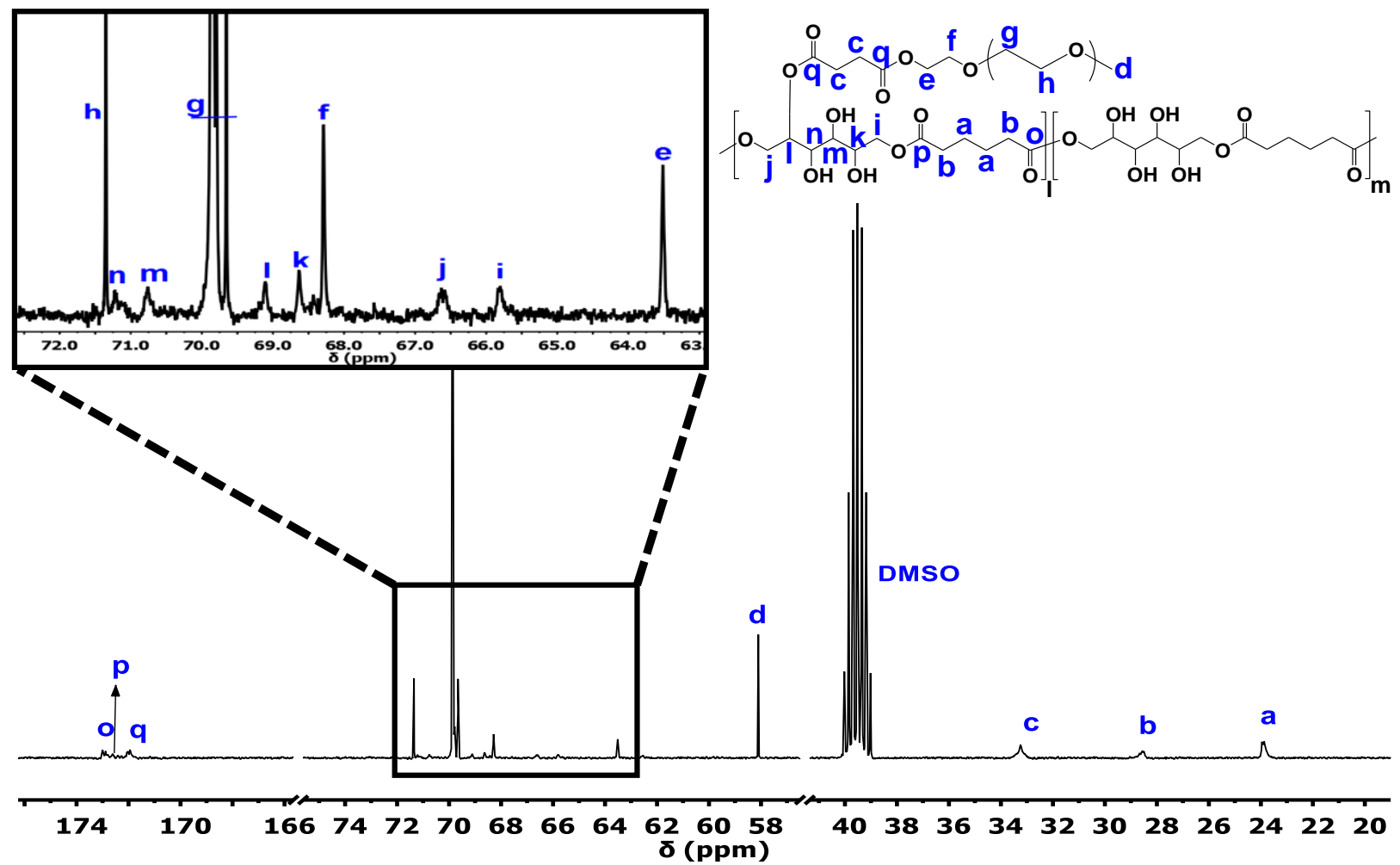

Figure 2. ${ }^{13} \mathrm{C}$ NMR spectrum of PSA- $g-\mathrm{mPEG}_{12}$ measured at $27{ }^{\circ} \mathrm{C}$ using DMSO- $\mathrm{d}_{6}$ as solvent.

The degree of grafting was calculated as $\sim 45 \mathrm{~mol} \%$ per polymer chain, i.e., nearly one out of eight $\mathrm{OH}$-groups is esterified with $\mathrm{mPEG}_{12}$-Suc. The degree of grafting can also be confirmed by taking the same ${ }^{1} \mathrm{H}$ NMR integrals of the mentioned peaks with $\mathrm{CDCl}_{3}$ as solvent, given in Figure S4 (Supplementary Materials).

The grafting was also verified by gel permeation chromatography (GPC) traces through a shift towards shorter retention time (Figure S5, Supplementary Materials). Suc$\mathrm{PEG}_{\mathrm{n}}$-Suc was synthesized through carboxylation of OH-PEG-OH on both sides with succinic anhydride. By the same procedure as followed for the synthesis of $\mathrm{mPEG}_{12}-\mathrm{Suc}_{\text {, }}$ esterification took place between $\mathrm{OH}-\mathrm{PEG}-\mathrm{OH}$ and succinic anhydride. Using Suc-PEG $\mathrm{n}^{-}$ Suc, with varying chain lengths of PEG, polymer networks were then prepared through Steglich esterification. Esterification took place between hydroxyl groups from PSA or PSA- $g-\mathrm{mPEG}_{12}$ and the carboxylate groups of the succinyl part of Suc-PEG $\mathrm{n}-\mathrm{Suc}$ in order to study the effect of different chain lengths of the cross-linkers on the overall behavior of the networks. An ideal network structure is given in Figure 3, while it can be verified by ${ }^{13}$ C CP MAS NMR spectra (Figure S6, Supplementary Materials). 


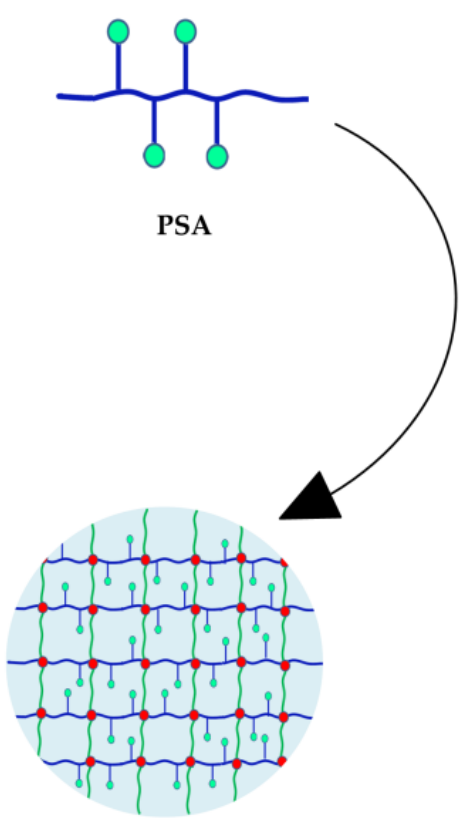

(a) PSA Network

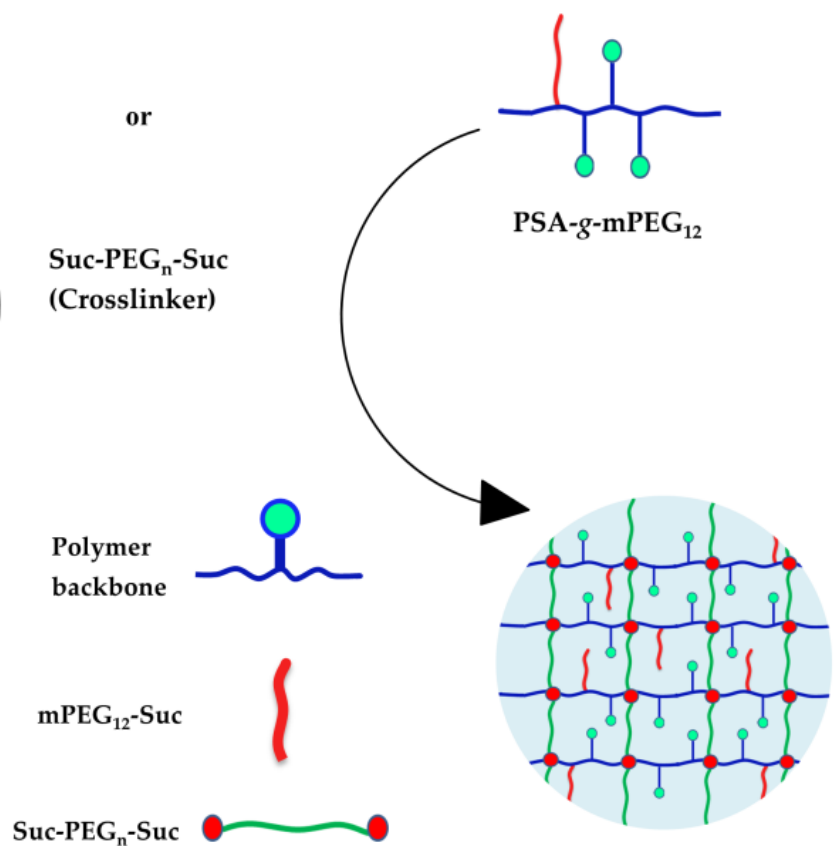

(b) PSA-g-mPEG ${ }_{12}$ Network

Figure 3. Presumed network formation using Suc-PEG - Suc with (a) PSA or (b) PSA-g-mPEG 12 when the network cross-links occur ideally.

\subsection{Differential Scanning Calorimetry}

Figure 4 and Table 1 summarize all DSC data taken in the range between $-60{ }^{\circ} \mathrm{C}$ and $80^{\circ} \mathrm{C}$. Figure $4 \mathrm{a}$ indicates the amorphous nature of PSA and PSA- $g-\mathrm{mPEG}_{12}$, since only a glass transition temperature $\left(T_{g}\right)$ is observed in the respective heating trace. In contrast, $\mathrm{mPEG}_{12}$-Suc shows a clear melting endotherm. Thus, the amorphous nature of PSA- $g-\mathrm{mPEG}_{12}$ indicates that the PSA backbone prevents the crystallization of the grafted PEG chains. PSA shows a $T_{g}$ at $-1{ }^{\circ} \mathrm{C}$ which is reduced to $-34{ }^{\circ} \mathrm{C}$ after grafting with $\mathrm{mPEG}_{12}-\mathrm{Suc}$, and resulting in PSA-g-mPEG 12 . The bifunctional cross-linker Suc-PEG $\mathrm{P}_{9}-\mathrm{Suc}$ also did not show any melting peaks but showed a $T_{g}$ at $-45{ }^{\circ} \mathrm{C}$ (see Figure $4 \mathrm{~b}$ ). When PSA was cross-linked with Suc-PEG $9-S u c$, the $T_{g}$ was lowered to $-11^{\circ} \mathrm{C}$. When PSA- $g-$ $\mathrm{mPEG}_{12}$ was cross-linked with Suc-PEG 9 -Suc, the $T_{g}$ appeared at $-29^{\circ} \mathrm{C}$. Both network structures cross-linked with Suc-PEGg-Suc did not show any melting peaks, demonstrating that the networks formed with Suc-PEG9-Suc were completely amorphous. In contrast, in networks formed with Suc-PEG $23-$ Suc and Suc-PEG $45-$ Suc, respectively, cross-linkers were semi-crystalline, indicated by their melting endotherms in the DSC traces, no matter if they were synthesized from PSA or PSA- $g-\mathrm{mPEG}_{12}$ (Figure $4 \mathrm{c}, \mathrm{d}$ ). Here, the crystallinity is obviously imparted by the cross-linkers Suc-PEG $23-\mathrm{Suc}$ and Suc-PEG $45-\mathrm{Suc}$, since they are also semi-crystalline. 

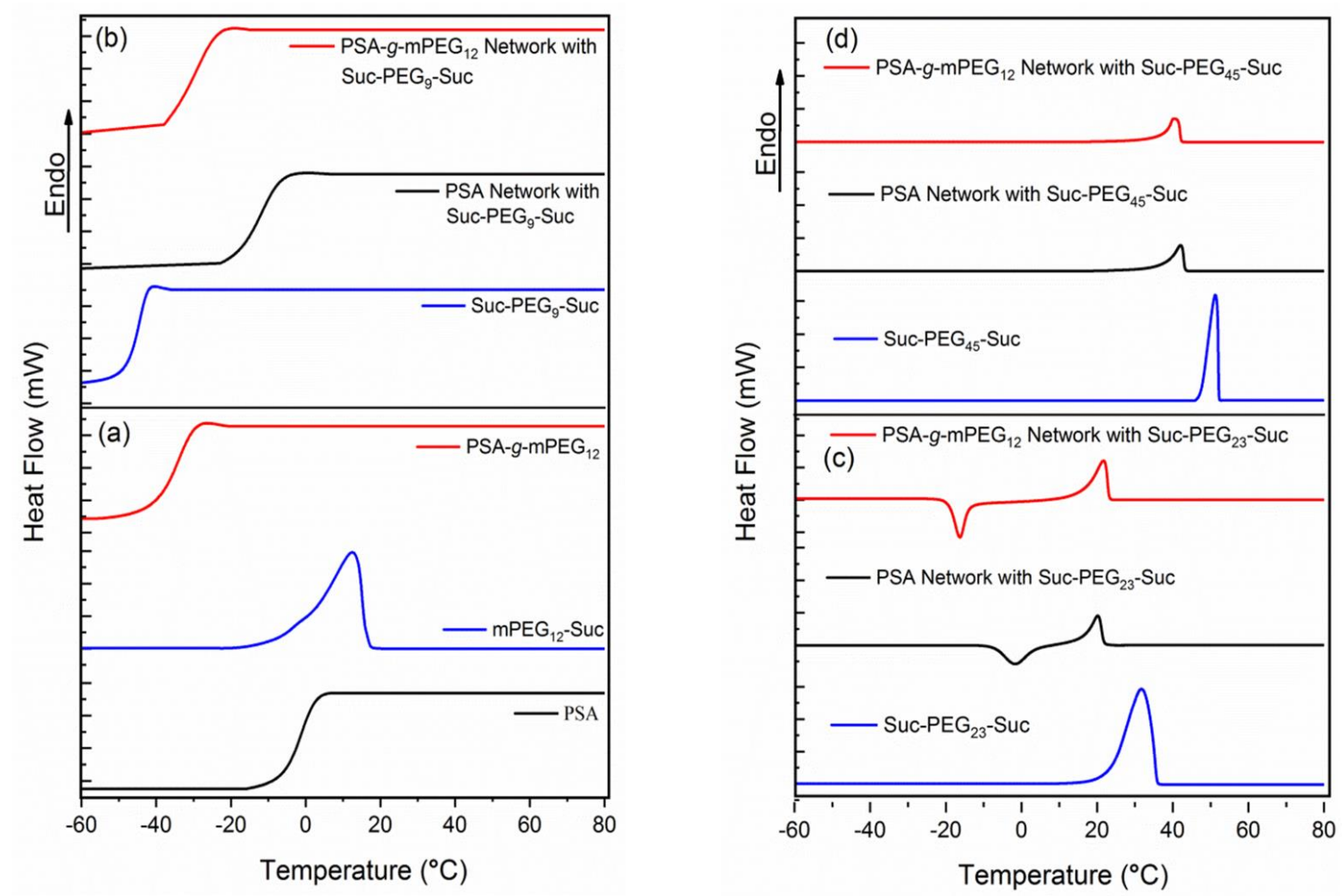

Figure 4. Differential scanning calorimetry (DSC) heating traces with a heating rate of $1{ }^{\circ} \mathrm{C} \cdot \mathrm{min}^{-1}$. (a) Polymers; PSA, $\mathrm{mPEG}_{12}$-Suc, and PSA-g-mPEG 12 , (b) Suc-PEGg-Suc (cross-linker), PSA networks crosslinked with Suc-PEG9-Suc, and PSA$g-\mathrm{mPEG}_{12}$ based networks cross-linked with Suc-PEG - -Suc, (c) Suc-PEG 23 -Suc (cross-linker), PSA networks cross-linked with Suc-PEG ${ }_{23}$-Suc, and PSA-g-mPEG 12 based networks cross-linked with Suc-PEG 23 -Suc, (d) Suc-PEG 45 -Suc (cross-linker), PSA networks cross-linked with Suc-PEG $45-$ Suc, and PSA-g-mPEG 12 based networks cross-linked with Suc-PEG $45-$ Suc. $_{2}$

Table 1. Number average molar mass $\left(M_{n}\right)$, dispersity $(\bigoplus)$, glass transition temperature $\left(T_{g}\right)$, melting temperature $\left(T_{m}\right)$, and melting enthalpy $\left(\Delta H_{m}\right)$ of polymer precursors and networks.

\begin{tabular}{|c|c|c|c|c|c|}
\hline Polymers and Networks & $M_{n}\left(\mathrm{~g} \cdot \mathrm{mol}^{-1}\right)$ & $\boxplus$ & $T_{\mathrm{g}}\left({ }^{\circ} \mathrm{C}\right)$ & $T_{m}\left({ }^{\circ} \mathrm{C}\right)$ & $\Delta H_{m}\left(\mathrm{~J} \cdot \mathrm{g}^{-1}\right)$ \\
\hline PSA & $11,000^{1}$ & $1.8^{3}$ & -1 & - & - \\
\hline $\mathrm{mPEG}_{12}$-Suc & $650^{4}$ & - & - & 12 & 45 \\
\hline $\mathrm{PSA}^{-} g-\mathrm{mPEG}_{12}$ & $22,000^{2}$ & $1.5^{3}$ & -34 & - & - \\
\hline Suc-PEG9-Suc & $600^{4}$ & - & -45 & - & - \\
\hline $\begin{array}{l}\text { PSA cross-linked with } \\
\text { Suc-PEGg-Suc }\end{array}$ & - & - & -11 & - & - \\
\hline $\begin{array}{l}\text { PSA-g-mPEG } 12 \text { cross-linked with } \\
\text { Suc-PEG } \text { Suc }_{9} \text {-Suc }\end{array}$ & - & - & -29 & - & - \\
\hline Suc-PEG $23-S u c$ & $1200^{4}$ & - & - & 31 & 86 \\
\hline $\begin{array}{l}\text { PSA cross-linked with } \\
\text { Suc- } \text { PEG }_{23} \text {-Suc }\end{array}$ & - & - & - & 20 & 23 \\
\hline $\begin{array}{c}\text { PSA-g-mPEG } \text { PE }_{12} \text { cross-linked with } \\
\text { Suc-PEG }{ }_{23}-\text { Suc }\end{array}$ & - & - & - & 22 & 40 \\
\hline Suc-PEG $45-$ Suc & $2200^{4}$ & - & - & 51 & 123 \\
\hline $\begin{array}{l}\text { PSA cross-linked with } \\
\text { Suc-PEG }{ }_{45}-\text { Suc }\end{array}$ & - & - & - & 42 & 32 \\
\hline $\begin{array}{l}\text { PSA-g-mPEG } 12 \text { cross-linked with } \\
\text { Suc-PEG } 45 \text {-Suc }\end{array}$ & - & - & - & 41 & 34 \\
\hline
\end{tabular}

\footnotetext{
${ }^{1}$ Molar mass of PSA is obtained by GPC measurements. ${ }^{2}$ Molar mass of graft copolymer (PSA-g-mPEG 12 ) is calculated on the basis of the degree of grafting obtained from ${ }^{1} \mathrm{H}$ NMR spectroscopy, and taking into account the molar mass of polymer (PSA) backbone obtained from GPC. ${ }^{3} Đ$ is calculated from GPC measurements. ${ }^{4} M_{n}$ is calculated from ${ }^{1} \mathrm{H}$ NMR spectroscopy.
} 
These traces also indicated a decrease in the melting temperature and melting enthalpies when the cross-linker molecules were located between PSA-based polymer backbones compared to the native cross-linker. For the PSA networks formed with Suc-PEG ${ }_{23}$ Suc, the phenomenon of cold-crystallization could also be observed [43]. Obviously, all networks formed by Suc-PEG9-Suc are amorphous, but when Suc-PEG 23 -Suc is employed for network formation, it needs some thermal activation so that the $P_{E G}{ }_{23}$-chains can form crystals. In the case of Sus- $\mathrm{PEG}_{45}$-Suc, the $\mathrm{PEG}_{45}$-chains are long enough to be packed into polymer crystals immediately after the synthesis of the networks. Furthermore, Suc-PEG $4_{5-}$ Suc based networks show higher melting temperatures compared to Suc-PEG ${ }_{23}-$ Suc based networks $[44,45]$.

\subsection{Swelling Studies}

Swelling studies of the networks were performed in $\mathrm{D}_{2} \mathrm{O}$ up to maximum water uptake (see Figure 5). This point can be considered as the equilibrium degree of swelling $[11,46]$. The studies revealed that the degree of swelling of all networks increased with the chain length of PEG based cross-linkers. There exists a nearly linear relation between the equilibrium degree of swelling and the degree of polymerization $n$ of the PEG-based bifunctional cross-linkers. Both PSA and PSA-g-mPEG 12 networks showed the highest degree of swelling when Suc-PEG 45 -Suc was used as cross-linker. In comparison to PSA networks, the PSA-g-mPEG 12 networks showed higher degrees of swelling, since the grafted PEG chains rendered the networks more hydrophilic. Figure 6 shows photographic images as examples of the different water uptake at room temperature. The images verify the two most important aspects of the swelling experiments: (i) The degree of swelling was larger for PSA-g-mPEG 12 samples compared to PSA based samples using identical crosslinkers; and (ii) The degree of swelling increased with the degree of polymerization $n$ of the cross-linker molecules when identical precursor polymers were employed, i.e., PSA and PSA-g-mPEG 12 , respectively.

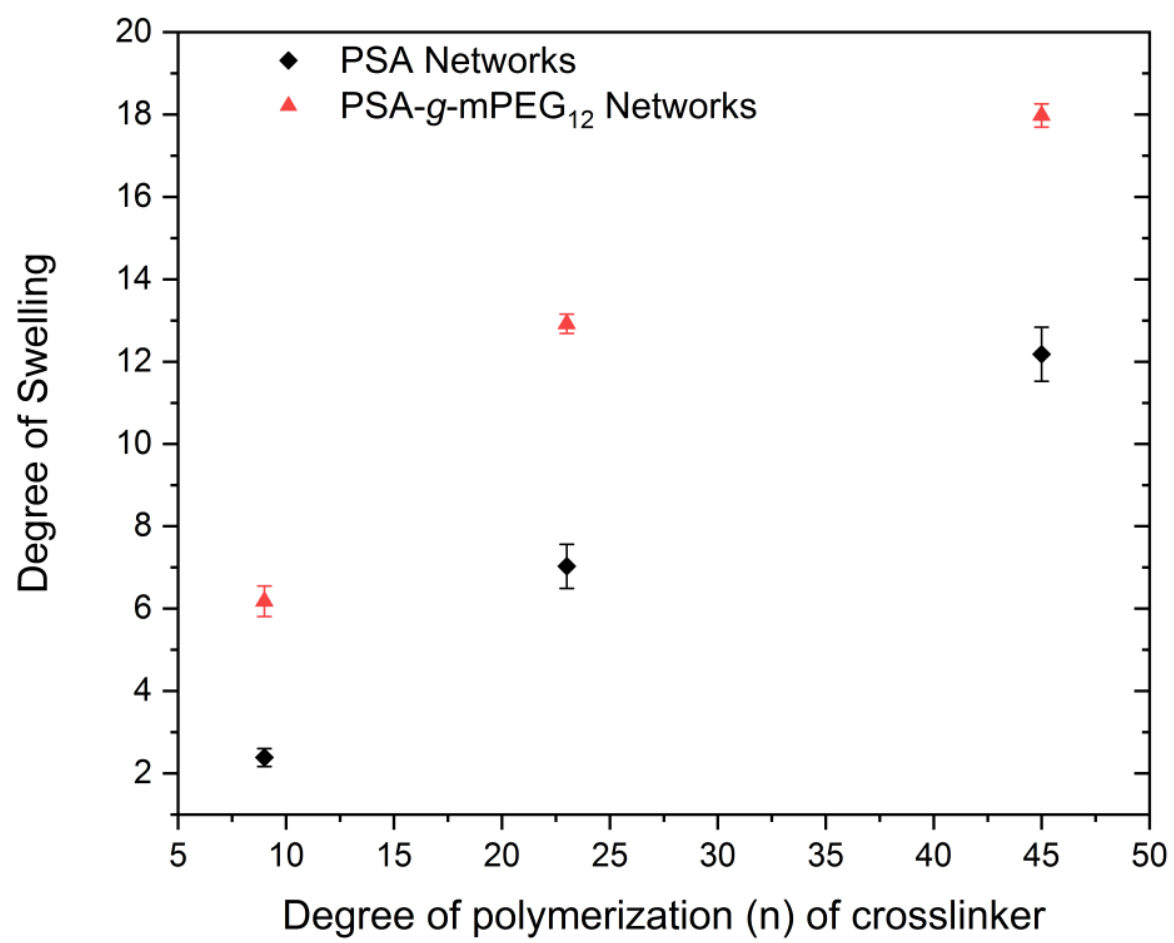

Figure 5. Degree of swelling of PSA and PSA- $g-\mathrm{mPEG}_{12}$ based networks as a function of degree of polymerization (n) in $\mathrm{D}_{2} \mathrm{O}$ at room temperature. 
(a)

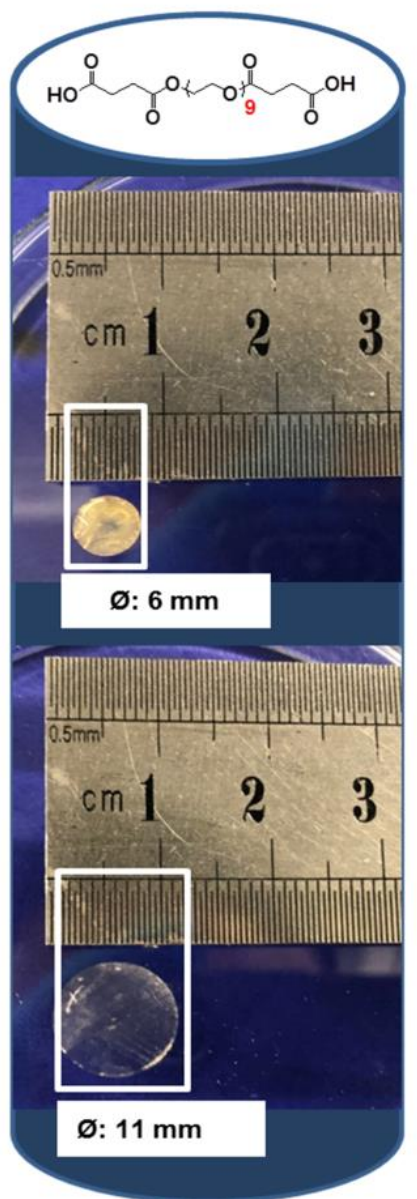

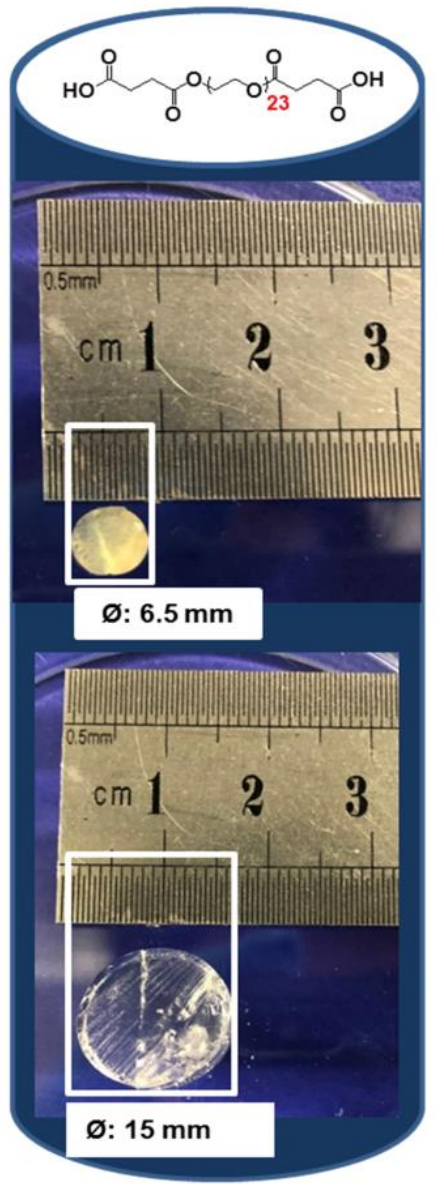

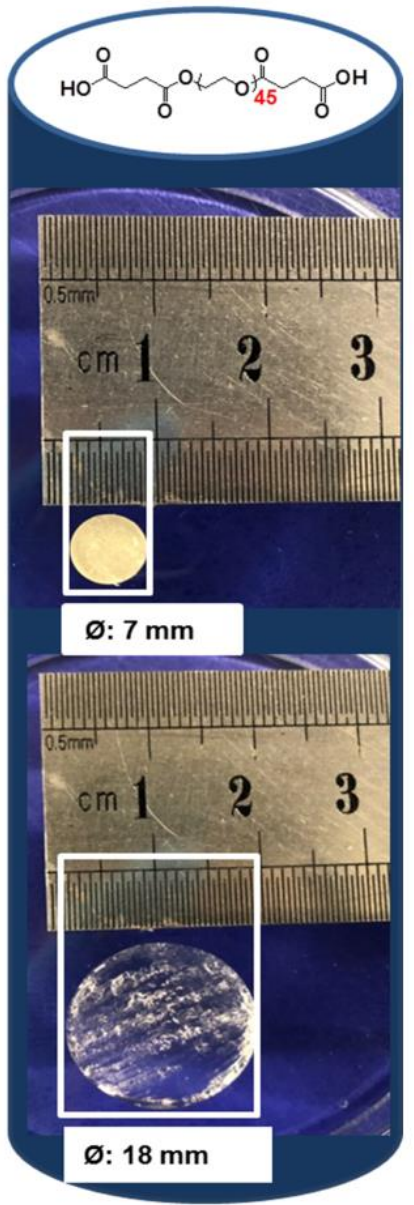

Figure 6. An example of change in the network diameter of disks of PSA- $g$ - $\mathrm{mPEG}_{12}$ networks cross-linked by (a) increasing molar mass of PEG based cross-linkers, when they are in (b) dry form, and (c) swollen form after $\mathrm{D}_{2} \mathrm{O}$ uptake.

\section{4. ${ }^{1} H$ Double-Quantum (DQ) NMR Spectroscopy}

For the characterization of the network samples, ${ }^{1} \mathrm{H}$ DQ measurements were performed. This method allows the analysis of the dynamics and the determination of the network structure. It also permits distinguishing the network-forming loops of different lengths, as well as various defects [47]. The exact details of the double-quantum (DQ) experiment and the pulse sequence according to Baum and Pines [48] used in this work can be taken from Ref. [49].

For the determination of the dipolar coupling constant, the mobile and uncoupled components, the so-called tail fraction, are first subtracted from the signal. Two-tail components are expected in a swollen real polymer network. The first is the solvent tail, which is caused by residual protons in the solvent, and since the samples contain an excess of $\mathrm{D}_{2} \mathrm{O}$, an increased amount of this component is expected. Second is the network tail, which is caused by the network defects, such as loops and dangling chain ends (unreacted chains).

For unmodified samples of PSA networks (Figure S7a-c, Supplementary Materials), the solvent tail could only be detected. Based on the long $T_{2}{ }^{*}$ decay time, it can be excluded that this component resulted from the network. The free chain ends of the main strands could not be detected. Note that the solvent tail did not correspond to the total amount of water in the sample. The DQ experiments were performed with a repetition time of $2 \mathrm{~s}$. This delay was chosen to be sufficient for the complete relaxation of the polymer, but was significantly shorter than $5 \cdot T_{1}$ of the solvent. Thus, the short recycling delay acted as a $T_{1}$ filter for the solvent, and the determined water content was lower than expected. 
Even in modified networks of PSA- $g$ - PEG $_{12}$, where about $~ 45 \%$ of the monomer units contained a side chain, no second tail component with a short $T_{2}{ }^{*}$ time could be detected (Figure S7d-f, Supplementary Materials). This result is surprising and indicates that the network tail, i.e., the free chain ends and other defects, did not differ in their mobility from the network structure. In other words, the isotropic mobility of the tail is restricted by the network.

To check the tail subtraction procedure, the normalized DQ intensity $\left(I_{n D Q}\right)$ was calculated (Figure S8, Supplementary Materials). The $n D Q$ intensity reaches the expected value of 0.5 for all samples, which is an indication that the correct tail fraction has been subtracted. It should be noted, however, that due to a complex network structure, the DQ data may contain not just one (as is the case of natural rubber), but several network components with different $T_{2}{ }^{*}$ values. This makes the $n D Q$ curves unsuitable for a quantitative evaluation, due to the incorrect normalization.

For this reason, the DQ data was directly evaluated with the help of a simultaneous fitting procedure. The PEG spacers as cross-linkers, which connect the main chains, are generally randomly distributed. This means that there are no loops of well-defined length like in Tetra-PEG [47] or other PEG networks [50], and this was the case in these samples. The mesh size can vary greatly, which leads to a broad distribution of dipolar couplings due to the relationship $D_{\text {res }} \propto M_{\mathcal{c}}$, the average molar mass between the cross-links. We tested both the Gaussian and log-normal distribution, and the latter showed a better fit to the measured data. The simultaneous fitting function for two network components is

$$
\begin{gathered}
I_{\Sigma D Q}\left(\tau_{D Q}\right)=\sum_{i=1}^{2} f_{i} \exp \left\{-\left(\tau_{D Q} / \tau_{i}\right)^{\beta_{i}}\right\} \\
I_{D Q}\left(\tau_{D Q}\right)=\sum_{i=1}^{2} \int_{0}^{\infty} I_{D Q}\left(\tau_{D Q}, D_{r e s}^{(i)}\right) p\left(D_{r e s}^{(i)}, \sigma^{(i)}\right) d D_{r e s}^{(i)} \\
I_{D Q}\left(\tau_{D Q}\right)=\sum_{i=1}^{2} \int_{0}^{\infty} \frac{1}{2} f_{i}\left[1-\exp \left\{-\left(0.378 \cdot D_{\text {res }}^{(i)} \tau_{D Q}\right)^{1.5}\right\} \cdot \cos \left(0.583 \cdot D_{r e s}^{(i)} \tau_{D Q}\right)\right] \cdot \exp \left\{-\left(\frac{\tau_{D Q}}{\tau_{i}}\right)^{\beta_{i}}\right\} \cdot p\left(D_{r e s}^{(i)}, \sigma^{(i)}\right) d D_{\text {res }}^{(i)}
\end{gathered}
$$

Fitting parameters are the component fraction $\left(f_{i}\right)$, the time constant $\left(\tau_{i}\right)$, which corresponds to the characteristic decay time $\left(T_{2}^{*}\right)$, the exponent $\beta$ of the Kohlrausch-WilliamsWatts (KWW) function, the residual dipolar coupling constant $D_{\text {res }}$, and the width of the log-normal distribution $\sigma$.

Table 2 summarizes the fitting results. The most important parameters are the component fractions $\left(f_{i}\right)$, the residual dipolar coupling constants $\left(D_{\text {res }}\right)$, and the distribution widths $(\sigma)$. The corresponding fitting curves are shown in Figure S9 (Supplementary Materials). Two network components with significantly different coupling constants were detected for all samples. The weakly coupled component dominated for all samples. With increasing length of the PEG spacers, the network became more mobile $\left(T_{2}{ }^{*}\right.$ value increases and $D_{\text {res }}$ decreases) and the proportion of more strongly coupled spins decreased. This applied generally to both PSA and PSA-g-mPEG 12 network batches.

The difference between PSA and PSA-g-mPEG 12 networks lies in the strength of the dipole coupling. As can be seen from Figure 7, PSA networks are more strongly coupled. However, the proportion of such strongly coupling protons is lower in PSA-g-mPEG 12 networks. In addition, there is a greater distribution width of the dipole couplings. The additional side chains thus lead to increasing inhomogeneity in the network. Not to be excluded is the case of phase separation, with areas of high and low polymer concentration. 
Table 2. Result of the simultaneous fitting to the double-quantum (DQ) data after the tail correction. The two network components are shown.

\begin{tabular}{|c|c|c|c|c|c|c|c|c|c|c|c|}
\hline $\begin{array}{l}\text { Polymer } \\
\text { Networks }\end{array}$ & $\begin{array}{l}\text { Crosslinking } \\
\text { Precursors }\end{array}$ & $f_{1}(\%)$ & $\begin{array}{l}T_{2}^{*} \\
(\mathrm{~ms})\end{array}$ & $\beta$ & $\begin{array}{c}D_{\text {res }} / 2 \pi \\
\quad(\mathrm{Hz})\end{array}$ & $\sigma$ & $f_{2}(\%)$ & $\begin{array}{l}T_{2}^{*} \\
(\mathrm{~ms})\end{array}$ & $\beta$ & $\begin{array}{l}D_{\text {res }} \\
/ 2 \pi \\
(\mathbf{H z})\end{array}$ & $\sigma$ \\
\hline \multirow{3}{*}{$\begin{array}{c}\text { PSA } \\
\text { Networks }\end{array}$} & Suc-PEG9-Suc & 37.0 & 5.2 & 2.0 & 462.5 & 0.46 & 63.0 & 7.8 & 1.5 & 131.3 & 0.49 \\
\hline & Suc-PEG ${ }_{23}-\mathrm{Suc}$ & 31.7 & 10.3 & 1.9 & 217.1 & 0.61 & 68.3 & 26.1 & 1.5 & 34.4 & 0.59 \\
\hline & Suc-PEG $45-S u c$ & 21.8 & 11.3 & 2.0 & 220.3 & 0.57 & 78.2 & 45.7 & 1.2 & 15.9 & 0.85 \\
\hline \multirow{3}{*}{$\begin{array}{c}\text { PSA-g- } \\
\text { mPEG }_{12} \\
\text { Networks }\end{array}$} & Suc-PEGg-Suc & 33.5 & 8.3 & 1.5 & 230.1 & 0.85 & 66.5 & 15.0 & 1.2 & 47.0 & 0.69 \\
\hline & Suc-PEG ${ }_{23}-S u c$ & 18.3 & 11.8 & 1.9 & 200.8 & 0.60 & 81.7 & 40.7 & 1.2 & 19.0 & 0.77 \\
\hline & Suc-PEG ${ }_{45}-$ Suc & 19.9 & 12.2 & 1.9 & 159.1 & 0.65 & 80.1 & 60.0 & 1.2 & 11.8 & 0.80 \\
\hline
\end{tabular}

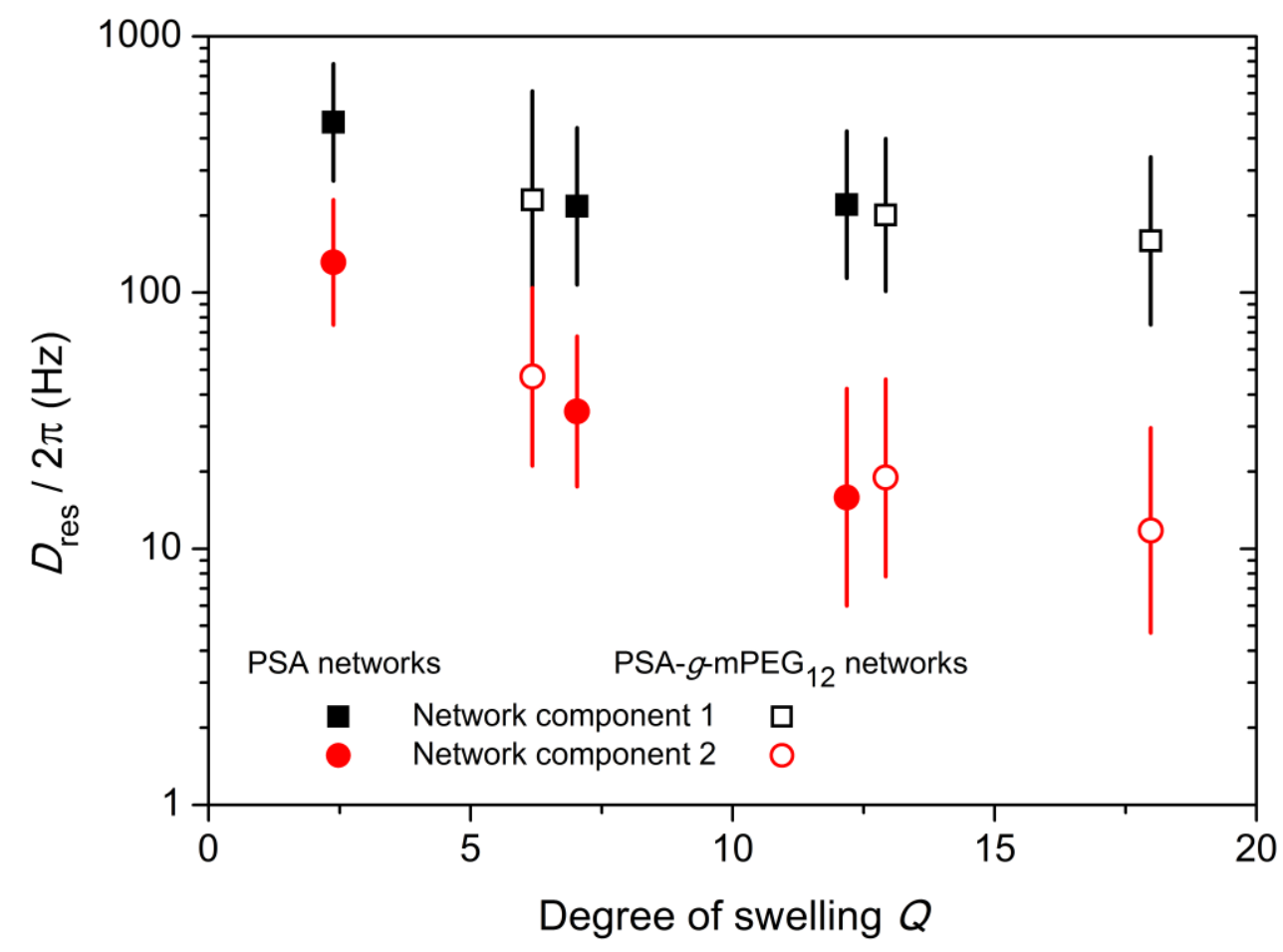

Figure 7. Relation between the dipolar coupling constant $\left(D_{\text {res }}\right)$ and the degree of swelling $(Q)$ of the samples. The vertical bars represent the distribution widths of $\sigma$ from the Table 2.

If the side chains and free chain ends are located in the first areas, they are less mobile and show a residual dipole coupling. This could explain the "invisible" tail in the PSA$g-\mathrm{mPEG}_{12}$ network samples. Keeping in view data from Table 2 and Figure 7 , dipolar coupling was decreasing, while $T_{2}{ }^{*}$ was increasing, causing mobility of the network. In other words, the increase in network mobility can be attributed to an increase of the degree of swelling, as shown in Figure 7.

\section{5. ${ }^{1} \mathrm{H}$ Pulsed Field Gradient (PFG) NMR Spectroscopy}

Furthermore, the diffusion of solvent molecules in swollen networks was investigated (See Figure 8). The samples were prepared without excess $\mathrm{D}_{2} \mathrm{O}$, so that diffusion outside the polymer network could be excluded. The measurement signal corresponded exclusively to the remaining HDO molecules in the polymer network. 


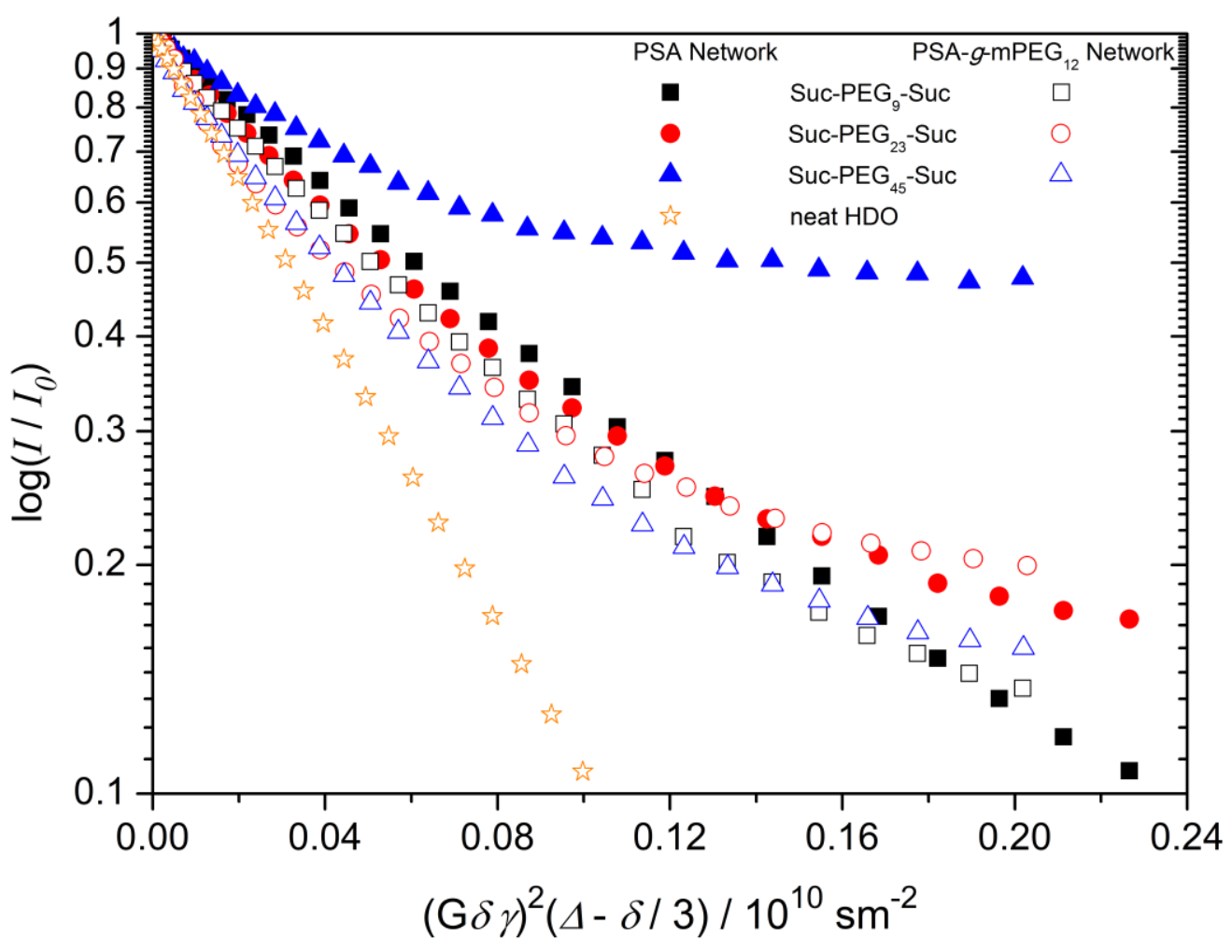

Figure 8. Normalized PFG NMR diffusion decays of HDO for different samples at $T=30^{\circ} \mathrm{C}$. Due to the intensity offset coming from the polymer signal, the initial slope does not reflect the translational diffusion coefficient of water $\left(D_{H D O}\right)$ in the polymer network correctly.

The ${ }^{1} \mathrm{H}$ spectra from the diffusion measurements are shown in Figure S10 (Supplementary Materials), and exhibit two well-resolved resonances. As the gradient strength $(G)$ increases, the intensity of the left peak decreases while the right peak remains constant. The assignment of the two resonances is therefore obvious. The left peak corresponds to the mobile solvent (HDO), while the right peak is assigned to the immobile polymer network (its diffusion can be neglected on the time scale of the diffusion of water). The relationship between the echo signal intensity and pulse field gradient parameters in the PFG experiment is given by

$$
I_{P F G}(G)=I_{P F G}(0) \cdot \exp \left(-\gamma^{2} G^{2} D \delta^{2}(\Delta-\delta / 3)\right)
$$

where $I_{P F G}$ is the echo signal intensity, $\gamma$ is the gyromagnetic ratio of the proton, $G$ is the field gradient strength during the gradient pulse of the length $(\delta), D$ is the self-diffusion coefficient, and $\Delta$ is the diffusion time [51].

The echo signal intensity was measured as a function of $G$. When plotting the logarithm of the echo intensity against the diffusion function $\gamma^{2} G^{2} \delta^{2}(\Delta-\delta / 3)$, the diffusion coefficient (D) can be determined from the slope of the curve.

In order to determine the diffusion coefficients of water, only the HDO peak was integrated. Figure 8 shows the normalized PFG diffusion decays of $\mathrm{HDO}$ of the investigated samples. In contrast to the diffusion of $\mathrm{HDO}$ in pure $\mathrm{D}_{2} \mathrm{O}$, the decay curves of the network samples showed a clear nonlinear behavior. This nonlinearity can be explained in two different ways. On one hand, it could be an anisotropic diffusion movement of water, e.g., caused by hydrogen bonding with the polymer. In this case, the evaluation of the diffusion data would be more difficult. However, if the diffusion length of an HDO molecule is calculated on the time scale of the diffusion measurement, it becomes clear that it is significantly larger than the dimensions of the smallest possible loop in the polymer network. The anisotropy of diffusion can thus be excluded. On the other hand, the non- 
linearity of the diffusion curves could be caused by a baseline problem in the spectrum. When looking closely at the spectra in Figure S11 (Supporting Materials), it becomes clear that the HDO peak overlaps with the network peak. This results in an offset in the diffusion curve, which must be taken into account. In this case, the upper formula is revised with a constant intensity offset. It is not necessary to add a second diffusion component, because the diffusion movement of the polymer network can be neglected on the time scale of the measurement. The strength of the background signal and thus the amount of offset depends on the spectral resolution and on the $T_{2}$ relaxation time of the polymer, and varies from sample to sample.

The determined diffusion coefficients are shown in Figure 9 as a function of the degree of swelling $Q$, and are in good agreement with the data reported for the poly( $N, N$-dimethylacrylamide) gels [52]. Especially at low swelling degrees, the network environment significantly influenced the normal diffusion movement of water. With increasing length of the PEG spacers, water diffusion in the polymer network became faster and approached the value of pure $\mathrm{D}_{2} \mathrm{O}$. In a direct comparison of the two network batches, it can be seen that the PSA- $g$ - PEG $_{12}$ networks could absorb more water, and therefore always showed higher diffusion coefficients for the same length of PEG spacers.

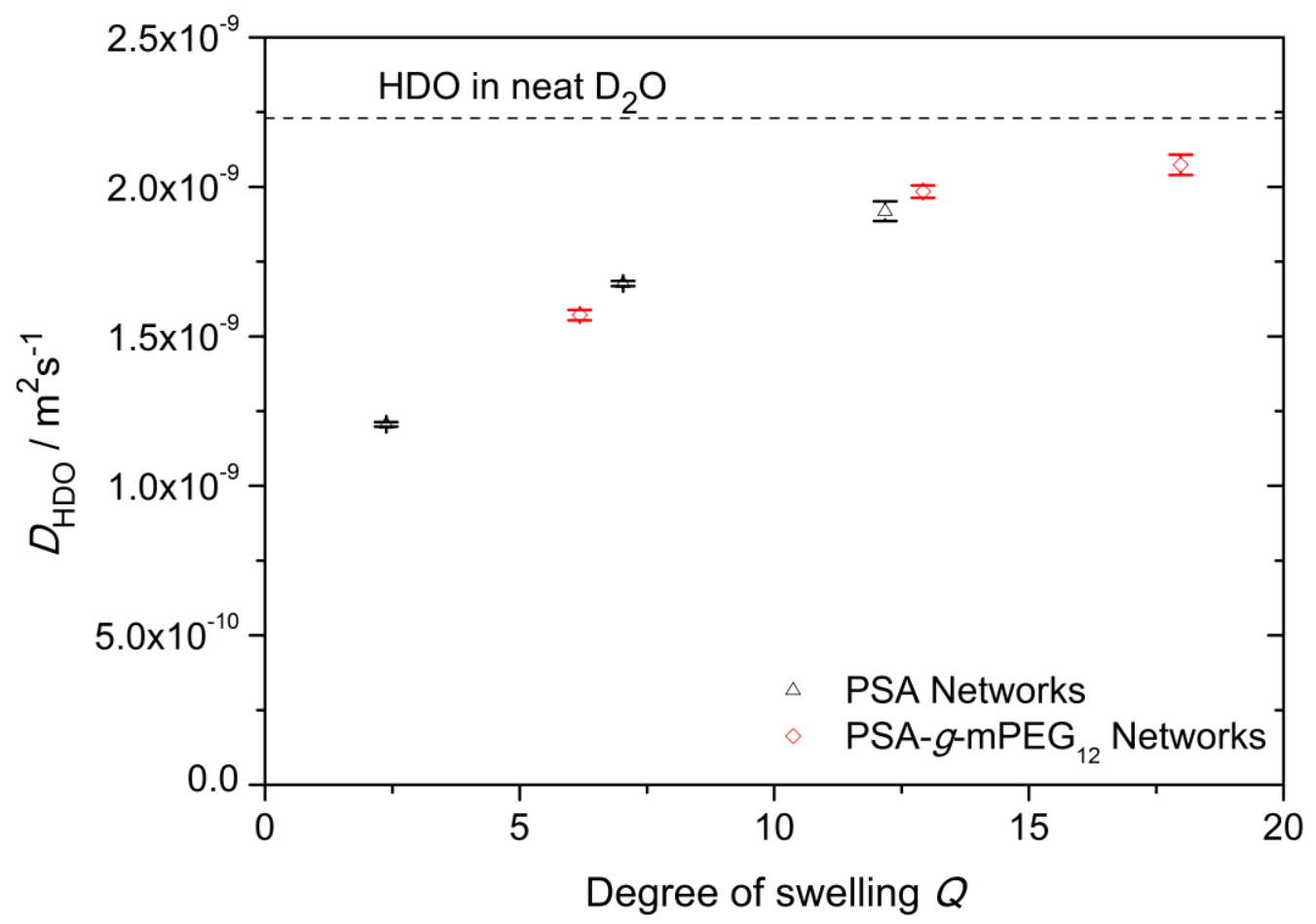

Figure 9. Dependence of the diffusion coefficient of water molecule $\left(D_{H D O}\right)$ on the degree of swelling $(Q)$ in PSA and PSA-g-mPEG 12 networks at $T=30{ }^{\circ} \mathrm{C}$. The dashed line represents the diffusion coefficient of HDO in neat $\mathrm{D}_{2} \mathrm{O}$ of $D_{H D O}=2.23 \cdot 10^{-9} \mathrm{~m}^{2} \cdot \mathrm{s}^{-1}$.

\section{Conclusions}

Enzymatic polymerization has been used as an alternative approach to produce green aliphatic polyesters, avoiding the drawbacks associated with conventional polymerization techniques. The presence of multiple hydroxyl groups on the PSA backbone not only allowed us to modify it with PEG side chains, but also to use these functional groups for the synthesis of polyester-based networks. All syntheses of PSA, $\mathrm{mPEG}_{12}-\mathrm{Suc}$, PSA-g-mPEG ${ }_{12}$, and Suc- $\mathrm{PEG}_{\mathrm{n}}$-Suc (bifunctional cross-linker) were confirmed through solution NMR spectroscopy. DSC data indicated the amorphous nature of PSA and PSA- $g-\mathrm{mPEG}_{12}$, and its influence on the melting temperatures of PEG segments in the networks incorporated by semi-crystalline cross-linker molecules. This shows that networks formed with low 
molar mass PEG cross-linkers (Suc-PEGg-Suc) are amorphous, while networks with high molar mass PEG cross-linkers (Suc-PEG ${ }_{23}$-Suc and Suc-PEG ${ }_{45}$-Suc) are semi-crystalline due to the crystallinity of the PEG based precursors. Furthermore, the degree of swelling of the network samples was directly related to the chain length of cross-linking agents. The structure and dynamics in PSA polymer networks were investigated by ${ }^{13} \mathrm{C}$ MAS and ${ }^{1} \mathrm{H}$ DQ NMR measurements. Experimental data indicated that the networks had an inhomogeneous structure. For both PSA and PSA-g-mPEG 12 networks, two network components with different dipolar coupling constants were detected. The exact amount of network defects could not be determined due to the inhomogeneity of the networks. ${ }^{1} \mathrm{H}$ PFG diffusion measurements on swollen networks allowed the determination of the diffusion coefficients of HDO in the networks. As expected, the diffusion of the solvent strongly depended on the degree of swelling of the sample. The modification of the PSA samples by PEG side chains led to increased swelling, and thus to faster diffusion in the network. Keeping in view the tunable characteristics of the networks as an exciting drug delivery system in general, as well as current physico-chemical data and the polymerization process in specific, potential pharmaceutical applications seem possible.

\section{Materials and Methods}

\subsection{Materials}

Novozyme 435, Lipase derived from Candida Antarctica type B (CAL-B) and immobilized on acrylic resin, was purchased from Sigma Aldrich, St. Louis, MO, USA. It was vacuum dried over phosphorous pentoxide for $24 \mathrm{~h}$ prior to use. Sorbitol (98\%) and divinyl adipate were purchased from Sigma Aldrich (Steinheim, Germany) and TCI GmbH (Eschborn, Germany), respectively. Phosphorous pentoxide ( $\geq 99 \%)$, 4-(dimethylamino)pyridine (DMAP), anhydrous $\mathrm{N}, \mathrm{N}$-dimethylformamide (DMF, 99.8\%), anhydrous tetrahydrofuran (THF, 99.9\%), 1-ethyl-3-(3-dimethylaminopropyl)carbodiimide hydrochloride (EDC. $\mathrm{HCl})$, dialysis membranes with $1000 \mathrm{~g} \cdot \mathrm{mol}^{-1}$ molar mass cut off (MWCO) and 10,000 $\mathrm{g} \cdot \mathrm{mol}^{-1}$ MWCO (Spectra/Por ${ }^{\circledR}$, made from regenerated cellulose) were purchased from Carl Roth, Karlsruhe, Germany. Deuterated chloroform $\left(\mathrm{CDCl}_{3}\right)$ and deuterated dimethyl sulfoxide (DMSO- $\mathrm{d}_{6}$ ) were purchased from Armar (Europa) $\mathrm{GmbH}$ (Leipzig, Germany). $\alpha, \omega$-bis-hydroxy poly(ethylene glycol $)_{n}\left(\mathrm{OH}-\mathrm{PEG}_{\mathrm{n}}-\mathrm{OH}\right.$, with $\mathrm{n}=9,23$, and 45$)$ and $\alpha$ methoxy, $\omega$-hydroxy poly(ethylene glycol $)_{12}\left(\mathrm{mPEG}_{12}-\mathrm{OH}\right)$ were purchased from Alfa Aesar (Kandel, Germany).

\subsection{Synthesis of Poly(Sorbitol Adipate) (PSA)}

PSA was synthesized by enzymatic polymerization, as described elsewhere [40]. In short, an equimolar amount of sorbitol $(10.0 \mathrm{~g}, 54.9 \mathrm{mmol})$ and divinyl adipate (DVA) $(10.88 \mathrm{~g}, 54.9 \mathrm{mmol})$ was added to a $250 \mathrm{~mL}$ three neck round bottom flask. The flask was connected with a reflux condenser with a calcium chloride drying tube and to a mechanical stirrer. It was then charged with $50 \mathrm{~mL}$ acetonitrile and stirred for $30 \mathrm{~min}$ at $50{ }^{\circ} \mathrm{C}$ until the temperature was equilibrated. Novozyme $435(2.1 \mathrm{~g}, 10 \% w / w$ of total mass of PSA and DVA) was then added to start the polymerization. The reaction mixture was stirred for $92 \mathrm{~h}$, and was then stopped and diluted with DMF followed by the removal of enzyme beads by filtration with Whatman ${ }^{\circledR}$ filter paper. The concentrated filtrate was processed through dialysis against deionized water for 7 days using a dialysis membrane with 1000 MWCO. Finally, the polymer solution was freeze dried to obtain the final pure product of PSA. The purity of the product was confirmed from ${ }^{1} \mathrm{H}$ NMR spectroscopy (Figure 1a). ${ }^{1} \mathrm{H}$ NMR (400 MHz, DMSO-d $\left.{ }_{6}\right) \delta(\mathrm{ppm}): 4.95-4.58(\mathrm{~m}, 2 \mathrm{H}), 4.57-4.33(\mathrm{~m}, 2 \mathrm{H}), 4.28-3.86(\mathrm{~m}$, $2 \mathrm{H}), 3.82-3.72(\mathrm{~m}, 2 \mathrm{H}), 3.61-3.34(\mathrm{~m}, 2 \mathrm{H}), 2.38-2.18(\mathrm{~m}, 4 \mathrm{H})$, and $1.61-1.41(\mathrm{~m}, 4 \mathrm{H})$.

\subsection{Synthesis of Mono- and Bifunctional PEG}

In a typical procedure to synthesize $\alpha, \omega$-bis-succinyl poly(ethylene glycol) (Suc- $\mathrm{PEG}_{\mathrm{n}}$ Suc) (with $n=9,23,45$ ) and $\alpha$-methoxy, $\omega$-succinyl poly(ethylene glycol) 12 (mPEG 12 -Suc), PEG was acylated by reaction with succinic anhydride through a procedure described 
elsewhere [53,54]. For the synthesis of $\mathrm{mPEG}_{12}-\mathrm{Suc}, \mathrm{mPEG}_{12}$ of molar mass $550 \mathrm{~g} \cdot \mathrm{mol}^{-1}$ was used, while for the synthesis of Suc-PEG $-\mathrm{Suc}, \mathrm{OH}-\mathrm{PEG}_{\mathrm{n}}-\mathrm{OH}$ having molar mass of $400 \mathrm{~g} \cdot \mathrm{mol}^{-1}, 1000 \mathrm{~g} \cdot \mathrm{mol}^{-1}$, and $2000 \mathrm{~g} \cdot \mathrm{mol}^{-1}$ were used, respectively. Suc-PEG $\mathrm{n}-\mathrm{Suc}{ }^{1} \mathrm{H}$ $\operatorname{NMR}\left(\left(400 \mathrm{MHz}, \mathrm{CDCl}_{3}\right) \delta(\mathrm{ppm})\right.$, Figures S12-S14, Supplementary Materials): $4.28-4.20(\mathrm{~m}$, $4 \mathrm{H}), 3.73-3.57$ ((m, 34H (Suc-PEG9-Suc); 92H (Suc- $\mathrm{PEG}_{23}$-Suc); $180 \mathrm{H}$ (Suc-PEG $\left.\left.{ }_{45}-\mathrm{Suc}\right)\right)$, 2.68$2.58(\mathrm{~m}, 8 \mathrm{H}) . \mathrm{mPEG}_{12}-\mathrm{Suc}^{1} \mathrm{H}-\mathrm{NMR}\left(\left(400 \mathrm{MHz}, \mathrm{CDCl}_{3}\right) \delta(\mathrm{ppm})\right.$, Figure $\mathrm{S} 3$, Supplementary Materials): $4.25-4.21(\mathrm{~m}, 2 \mathrm{H}), 3.68-3.51(\mathrm{~m}, 50 \mathrm{H}), 3.35(\mathrm{~s}, 3 \mathrm{H}), 2.67-2.56(\mathrm{~m}, 4 \mathrm{H})$.

\subsection{Synthesis of $P S A-g-m P E G_{12}$}

PEG was introduced as a side chain to PSA through Steglich esterification, by reacting pendant hydroxyl groups of PSA and carboxyl groups from $\mathrm{mPEG}_{12}$-Suc. The overall procedure was as follows: PSA $(2.0 \mathrm{~g}, 27.3 \mathrm{mmol})$ and $\mathrm{mPEG}_{12}$-Suc $(2.67 \mathrm{~g}, 4.11 \mathrm{mmol})$ were charged into a two neck round bottom flask together with anhydrous DMSO. DMAP $(0.15 \mathrm{~g}$, $1.2 \mathrm{mmol})$ and $\mathrm{EDC} \cdot \mathrm{HCl}(2.35 \mathrm{~g}, 12.3 \mathrm{mmol})$ were added as catalysts to the reaction mixture. It was stirred for $24 \mathrm{~h}$ at room temperature. The crude product was then purified by dialyzing it in deionized water through a dialysis membrane for 5 days, using a membrane with MWCO 10,000 $\mathrm{g} \cdot \mathrm{mol}^{-1}$. The diluted product solution was then freeze dried to obtain the final product. ${ }^{1} \mathrm{H}$ NMR $\left(\left(400 \mathrm{MHz}, \mathrm{DMSO}-\mathrm{d}_{6}\right) \delta(\mathrm{ppm})\right.$ (Figure $\left.\left.1 \mathrm{~b}\right)\right): 4.95-4.58(\mathrm{~m}, 2 \mathrm{H})$, 4.57-4.33 (m, 2H), 4.16-4.08 (m, 2H), 4.28-3.86 (m, 3H), 3.82-3.72 (m, 2H), 3.56-3.45 (m, $50 \mathrm{H}), 3.23(\mathrm{~s}, 3 \mathrm{H}), 2.61-2.52(\mathrm{~m}, 4 \mathrm{H}), 3.61-3.34(\mathrm{~m}, 2 \mathrm{H}), 2.38-2.18(\mathrm{~m}, 4 \mathrm{H}), 1.61-1.41(\mathrm{~m}, 4 \mathrm{H})$.

\subsection{Network Syntheses of PSA or PSA-g-mPEG 12 with Suc-PEG $n^{-S u c}$}

Networks were synthesized by esterifying free hydroxyl groups from PSA or PSA$g$-mPEG 12 with carboxyl groups of Suc- $\mathrm{PEG}_{\mathrm{n}}$-Suc (with $\mathrm{n}=9$, 23, 45) using Steglich esterification as shown in Scheme 1. In a typical experiment, PSA $(0.500 \mathrm{~g}, 6.85 \mathrm{mmol})$ was first dissolved in DMSO followed by the addition of DMAP $(0.17 \mathrm{~g}, 1.36 \mathrm{mmol})$ and $\mathrm{EDC} \cdot \mathrm{HCl}(2.61 \mathrm{~g}, 13.69 \mathrm{mmol})$ in a vial. At the end, Suc-PEG9-Suc (1.23 g, $2.05 \mathrm{mmol})$ was added to the above reaction mixture and kept overnight at $37^{\circ} \mathrm{C}$ to obtain PSA gels.

A similar procedure was adopted to synthesize networks from PSA-g-mPEG 12 . For

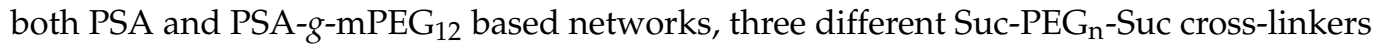
with varying chain lengths were used (with $n=9,23,45$ ). The same concentration, i.e., $30 \mathrm{~mol} \%$ of cross-linker with respect to free hydroxyl groups available at the polymer backbone, was used for the syntheses of both types of network. The gels were then cut into discs and washed with deionized water as washing medium, with repeated replacements 3 times per day. The washing process was continued for 7 days in order to remove all impurities present in the networks. Purified swollen network discs were then dried in a vacuum oven at $37^{\circ} \mathrm{C}$ to obtain the dry and clean product. The synthesis scheme for polymer precursors and network formation are also given in Scheme 1. 
(a) Synthesis of poly(sorbitol adipate) backbone:

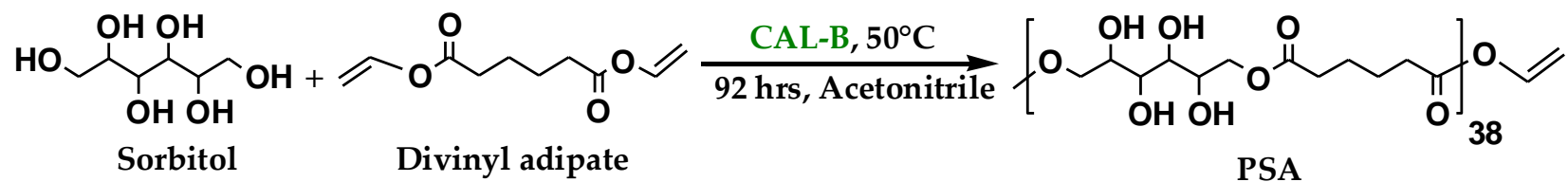

(b) Synthesis of PSA-g-mPEG 12 :

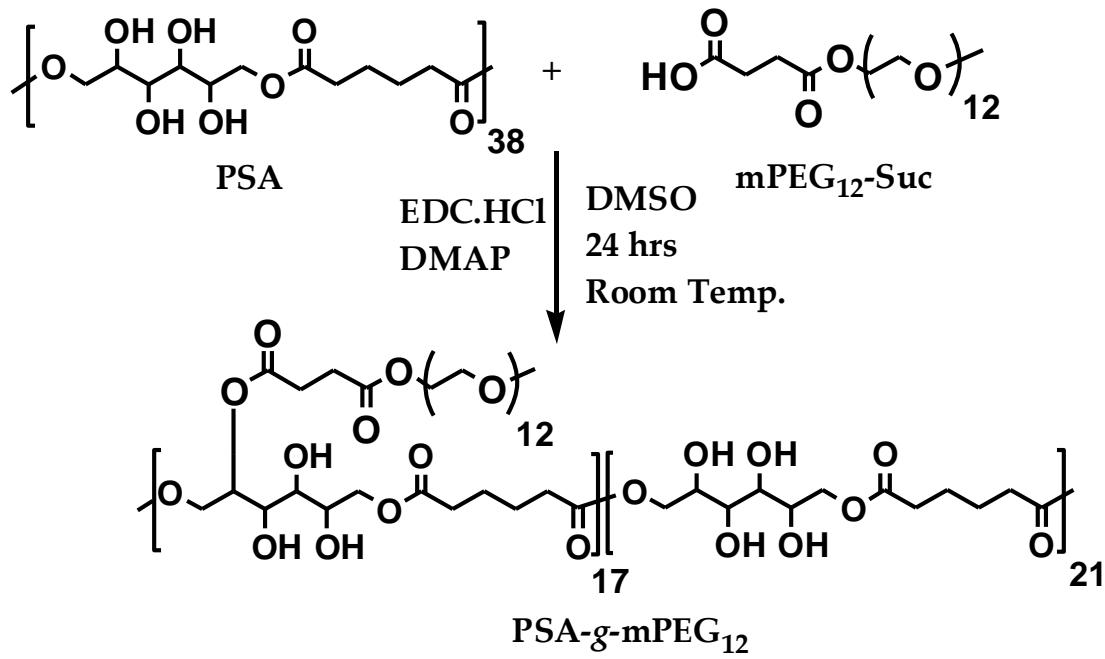

(c) Synthesis of PSA and PSA-g-mPEG ${ }_{12}$ networks through Suc-PEG ${ }$-Suc Crosslinker:
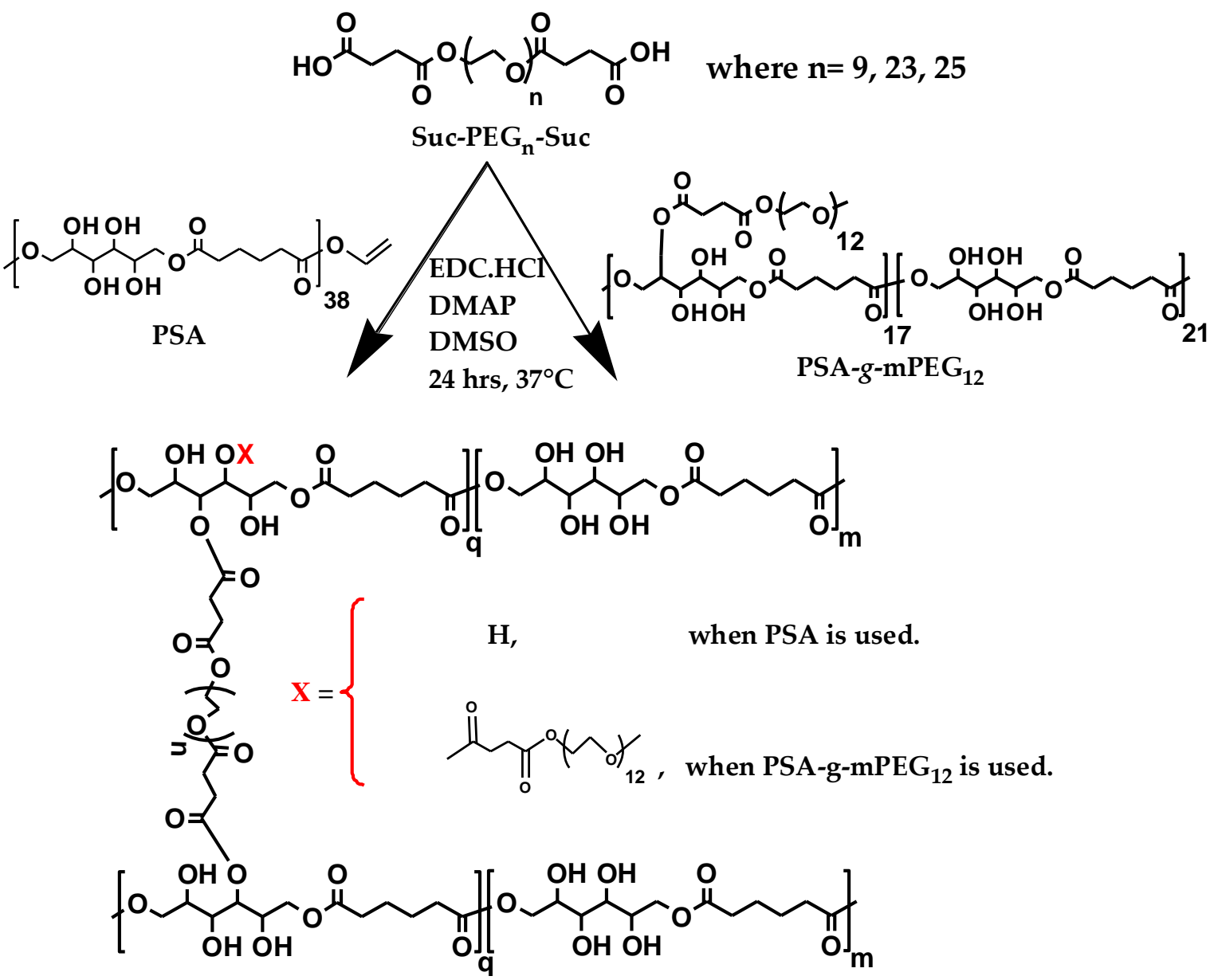

Scheme 1. Synthesis route to network formation from PSA and PSA-g-mPEG 12 . 


\subsection{Nuclear Magnetic Resonance (NMR) Spectroscopy \\ 4.6.1. Solution NMR Spectroscopy}

Solution NMR spectroscopy $\left({ }^{1} \mathrm{H}\right.$ NMR and ${ }^{13} \mathrm{C}$ NMR $)$ was performed using an Agilent VNMRS spectrometer $400 \mathrm{MHz}$ at $27^{\circ} \mathrm{C}$. Tetramethylsilane (TMS) was used as internal calibration standard. Deuterated solvents, $\mathrm{DMSO}-\mathrm{d}_{6}$ and $\mathrm{CDCl}_{3}$, were used for measuring the spectra of the polymers. Measurements were evaluated through MestReNova software (version 11.0.4), developed by Mestrelab Research, Spain, while the peaks were assigned using ChemDraw Ultra software (version 7.0), developed by CambridgeSoft Corporation, Cambridge, MA, USA.

\subsubsection{Solid State NMR Spectroscopy \\ ${ }^{13} \mathrm{C}$ Magic Angle Spinning (MAS) NMR Spectroscopy}

${ }^{13} \mathrm{C}$ MAS cross-polarization (CP) and single-pulse (SP) experiments were performed on a Bruker Avance 400 spectrometer, operating at a ${ }^{13} \mathrm{C}$ Larmor frequency of $100 \mathrm{MHz}$. A $4 \mathrm{~mm}$ triple-resonance probe head was used and a MAS spinning frequency of $10 \mathrm{kHz}$ was applied in all experiments. The sample temperature was controlled by a standard Bruker VT-controller and calibrated with methanol. For all experiments, the temperature was set to $30{ }^{\circ} \mathrm{C}$. The ${ }^{13} \mathrm{C} \pi / 2$ pulse length varied between 2.5 and $3.0 \mu$ s. The recycle delay was chosen so as to meet the condition of $5 \cdot T_{1}$ of protons, to allow complete restoration of the initial signal. The corresponding relaxation times were estimated by means of the saturation-recovery pulse sequence. Dry samples were filled into a Kel-F insert for a standard $4 \mathrm{~mm}$ rotor. The spectrum was referenced according to the COO resonance of alanine. The line assignment was carried out using ChemDraw Ultra software (version 7.0) developed by CambridgeSoft Corporation, USA.

\section{${ }^{1} \mathrm{H}$ Double Quantum (DQ) NMR Spectroscopy}

${ }^{1} \mathrm{H}$ DQ NMR experiments were performed on a Bruker Avance III $200 \mathrm{MHz}$ spectrometer using a static $5 \mathrm{~mm}$ Bruker probe. The temperature was controlled with a BVT-3000 heating-device with an accuracy of $\pm 1{ }^{\circ} \mathrm{C}$. For all experiments, the temperature was set to $30^{\circ} \mathrm{C} .{ }^{1} \mathrm{H} \pi / 2$ pulse of $3 \mu \mathrm{s}$ length and recycle delay of $2 \mathrm{~s}$ were applied. For the DQ measurements, samples were swollen in $\mathrm{D}_{2} \mathrm{O}$ to equilibrium and then filled into $5 \mathrm{~mm}$ glass tubes. A small amount of $\mathrm{D}_{2} \mathrm{O}$ was added to prevent the samples from drying out during the long measurement. Afterwards the tube was sealed.

\section{${ }^{1} \mathrm{H}$ Pulsed Field Gradient (PFG) NMR Spectroscopy}

${ }^{1} \mathrm{H}$ PFG NMR spectroscopy was carried out for diffusion coefficient measurements. The spectra were recorded with a Bruker Avance II $400 \mathrm{MHz}$ instrument at $30{ }^{\circ} \mathrm{C}$. A stimulated echo with bipolar gradient (STEBP) was used as sequence with gradient time $\delta$ of $1-2 \mathrm{~ms}$ and a varying diffusion time $\Delta$ of $20-80 \mathrm{~ms}$, depending on the sample. ${ }^{1} \mathrm{H}$ $\pi / 2$ pulse length between 3.0 and $3.5 \mu$ s and recycle delays of at least $5 \cdot T_{1}$ were applied. Samples swollen in $\mathrm{D}_{2} \mathrm{O}$ to equilibrium were filled into $5 \mathrm{~mm}$ glass tubes. The amount of HDO molecules in deuterated water is sufficient to obtain a good signal, which is comparable in intensity to the signal from the network. No additional $\mathrm{D}_{2} \mathrm{O}$ was added. This ensures that there was no signal contribution from free water outside the network. Since the diffusion measurements usually take a few hours, and were performed at room temperature, the drying of the samples could be neglected.

\subsection{Gel Permeation Chromatography (GPC)}

GPC measurements were performed using a Viscotek GPCmax VE 2002 having columns of HHRH Guard-17360 and GMHHR-N-18055 with refractive index detector (VE 3580 RI detector, Viscotek) at room temperature. DMF with the addition of $0.01 \mathrm{M} \mathrm{LiBr}$ was used as an eluent with a sample concentration of $5 \mathrm{mg} \cdot \mathrm{mL}^{-1}$. Poly (methyl methacrylate) (PMMA) was used as calibration standard and the flow rate was $1 \mathrm{~mL} \cdot \mathrm{min}^{-1}$. The number 
of average molar mass $\left(M_{n}\right)$, the weight average molar mass $\left(M_{w}\right)$, and the dispersity $(\nexists$, $M_{w} / M_{n}$ ) were determined.

\subsection{Differential Scanning Calorimetry (DSC)}

The thermal analysis of all precursor polymers and networks was carried out using a DSC, Mettler Toledo DSC823e module, Mettler-Toledo GmbH, Greifensee, Switzerland. Pre-weighed samples were placed in aluminum crucibles and were scanned against temperature ranging from $-60^{\circ} \mathrm{C}$ to $80^{\circ} \mathrm{C}$. A heating rate of $1{ }^{\circ} \mathrm{C} \cdot \mathrm{min}^{-1}$ was employed and the nitrogen flow rate was $10 \mathrm{~mL} \cdot \mathrm{min}^{-1}$.

\subsection{Swelling Studies}

Dried network discs were investigated for solvent uptake studies in $\mathrm{D}_{2} \mathrm{O}$. In a typical experiment, pre-weighed dry network samples were immersed into water and allowed to swell for $24 \mathrm{~h}$ at room temperature until they reached their equilibrium state. Swollen discs of both PSA and PSA-g-mPEG 12 based networks were then taken out and rolled over blotting paper in order to remove water from the surface and then weighed. The degree of swelling at equilibrium swelling was finally calculated by taking into account the weights of dry and swollen samples. Measurement was done in triplicate. The degree of swelling was calculated using Equation (6).

$$
\text { Degree of swelling }=\frac{m_{t}-m_{0}}{m_{o}}
$$

where, $m_{t}$ refers to the swollen network, while $m_{0}$ refers to the dried network disc.

Supplementary Materials: The following are available online at https:/ /www.mdpi.com/2310-2 $861 / 7 / 1 / 22 / s 1$, Figure S1. $13 \mathrm{C}$ NMR spectra of poly (sorbitol adipate) measured at $27^{\circ} \mathrm{C}$ using DMSO-d6 as solvent. Figure S2. 13C CP (top) and SP (bottom) MAS spectra of poly(sorbitol adipate). Scheme S1. Synthesis scheme of mPEG12-Suc. Figure S3. 1H NMR spectra of mPEG12-Suc measured at $27^{\circ} \mathrm{C}$ using $\mathrm{CDCl} 3$ as solvent. Figure S4. $1 \mathrm{H}$-NMR spectra of PSA-g-mPEG12 measured at $27^{\circ} \mathrm{C}$ using $\mathrm{CDCl} 3$ as solvent. Figure S5. GPC traces of PSA before and after modification with mPEG12Suc. Figure S6. 13C SP spectra of PSA and PSA-g-mPEG12 networks with a Suc-PEG9-Suc crosslinker. Figure S7. Determination of the tail fraction through $1 \mathrm{H}$ DQ NMR for $(\mathrm{a}-\mathrm{c})$ PSA networks crosslinked with the Suc-PEGn-Suc (where $n=9,23,45$ ) and (d-f) PSA-g-mPEG12 networks crosslinked with the Suc-PEGn-Suc (where $n=9,23,45$ ). Figure S8. Normalized double quantum curves $n D Q$ through $1 \mathrm{H}$ DQ NMR for (a-c) PSA networks crosslinked with the Suc-PEGn-Suc (where $\mathrm{n}=9,23,45$ ) and (d-f) PSA-g-mPEG12 networks crosslinked with the Suc-PEGn-Suc (where $n=9,23$, 45). Figure S9. Simultaneous fitting to the sum intensity I $\Sigma$ and DQ intensity IDQ through $1 \mathrm{H}$ DQ NMR after tail correction for $(\mathrm{a}-\mathrm{c})$ PSA networks crosslinked with the Suc-PEGn-Suc (where $\mathrm{n}=9,23,45)$ and $(\mathrm{d}-\mathrm{f})$ PSA-g-mPEG12 networks crosslinked with the Suc-PEGn-Suc (where $n=9,23,45$ ). Figure S10. $1 \mathrm{H}$ NMR spectra measured with PFG NMR spectroscopy of PSA-g-mPEG12 network (Suc-PEG9-Suc) with $\mathrm{Q}=6.2$ and $\mathrm{D} 2 \mathrm{O}$ as solvent by varying field gradient strength at $\mathrm{T}=30^{\circ} \mathrm{C}$. Figure S11. Fit example for the network sample crosslinked with Suc-PEG45-Suc according to eq.2. Scheme S2. Synthesis scheme of Suc-PEGn-Suc. Figure S12. 1H NMR spectra of Suc-PEG9-Suc measured at $27^{\circ} \mathrm{C}$ using $\mathrm{CDCl} 3$ as solvent. Figure S13. $1 \mathrm{H}$ NMR spectra of Suc-PEG23-Suc measured at $27^{\circ} \mathrm{C}$ using $\mathrm{CDCl} 3$ as solvent. Figure S14. 1H NMR spectra of Suc-PEG45-Suc measured at $27^{\circ} \mathrm{C}$ using CDCl3 as solvent.

Author Contributions: Conceptualization, H.R. and J.K.; methodology, H.R., Y.G. and M.H.B.; software, H.R. and Y.G.; formal analysis and investigation, H.R. and Y.G.; writing-review and editing, H.R., Y.G., M.H.B., K.M., D.R. and J.K.; supervision, K.M., D.R. and J.K. All authors have read and agreed to the published version of the manuscript.

Funding: This research was funded by Higher Education Commission of Pakistan (HEC PAK) (Ref. PD/OS-II/Batch-VI/Germany/2015/77159/17755), Deutscher Akademischer Austauschdienst (DAAD) Germany and Deutsche Forschungsgemeinschaft (DFG) Germany (DFG KR 1714/9-2 \& RE 1025/19-2, project number: 245736274). 
Conflicts of Interest: The authors declare no conflict of interest.

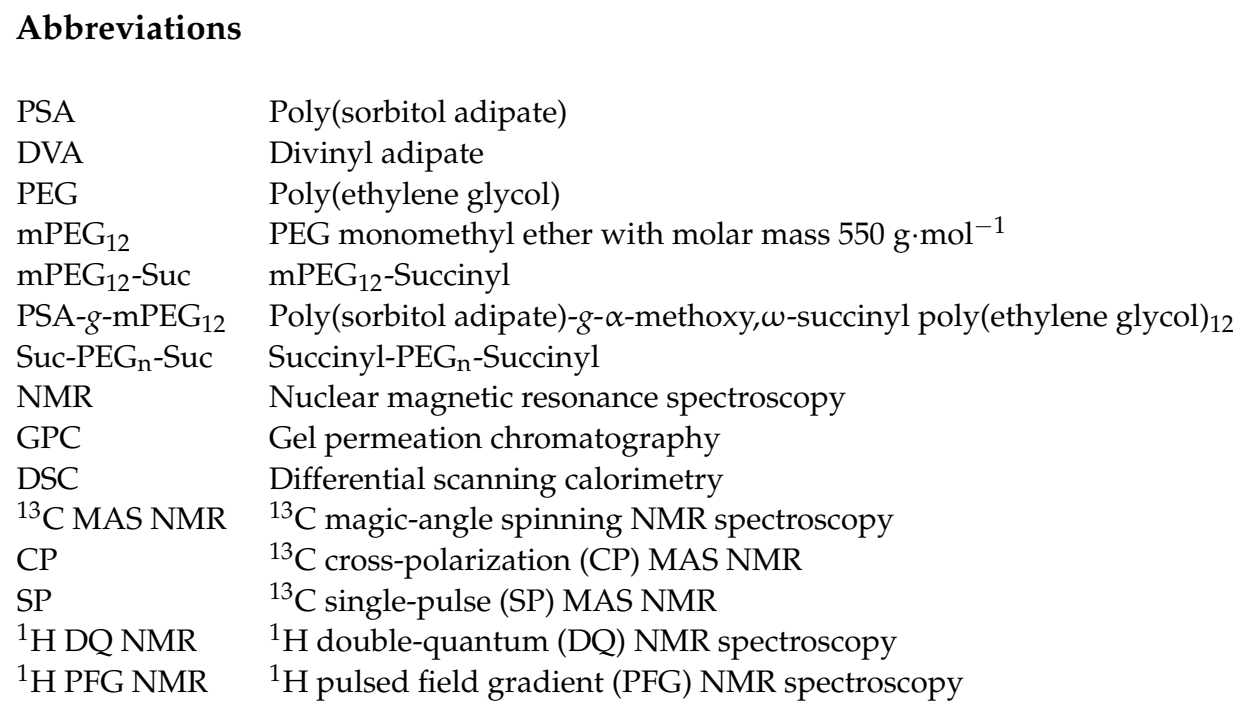

\section{References}

1. Xiang, H.P.; Qian, H.J.; Lu, Z.Y.; Rong, M.Z.; Zhang, M.Q. Crack healing and reclaiming of vulcanized rubber by triggering the rearrangement of inherent sulfur crosslinked networks. Green Chem. 2015, 17, 4315-4325. [CrossRef]

2. Xu, C.; Cui, R.; Fu, L.; Lin, B. Recyclable and heat-healable epoxidized natural rubber/bentonite composites. Compos. Sci. Technol. 2018, 167, 421-430. [CrossRef]

3. Li, J.; Mooney, D.J. Designing hydrogels for controlled drug delivery. Nat. Rev. Mater. 2016, 1, 16071. [CrossRef]

4. Hoffman, A.S. Hydrogels for biomedical applications. Adv. Drug Deliv. Rev. 2012, 64, 18-23. [CrossRef]

5. Buwalda, S.J.; Boere, K.W.M.; Dijkstra, P.J.; Feijen, J.; Vermonden, T.; Hennink, W.E. Hydrogels in a historical perspective: From simple networks to smart materials. J. Control. Release 2014, 190, 254-273. [CrossRef]

6. Gu, Y.; Zhao, J.; Johnson, J.A. Polymer Networks: From Plastics and Gels to Porous Frameworks. Angew. Chem.-Int. Ed. 2020, 59, 5022-5049. [CrossRef]

7. Hennink, W.E.; van Nostrum, C.F. Novel crosslinking methods to design hydrogels. Adv. Drug Deliv. Rev. 2012, 64, 223-236. [CrossRef]

8. Tibbitt, M.W.; Anseth, K.S. Hydrogels as extracellular matrix mimics for 3D cell culture. Biotechnol. Bioeng. 2009, 103, 655-663. [CrossRef]

9. Beria, L.; Gevrek, T.N.; Erdog, A.; Sanyal, R.; Pasini, D.; Sanyal, A. "Clickable” hydrogels for all: Facile fabrication and functionalization. Biomater. Sci. 2014, 2, 67-75. [CrossRef]

10. Peppas, N.A.; Bures, P.; Leobandung, W.; Ichikawa, H. Hydrogels in pharmaceutical formulations. Eur. J. Pharm. Biopharm. 2000, 50, 27-46. [CrossRef]

11. Holback, H.; Yeo, Y.; Park, K. Hydrogel swelling behavior and its biomedical applications. In Biomedical Hydrogels: Biochemistry, Manufacture and Medical Applications; Elsevier: Amsterdam, The Netherlands, 2011; pp. 3-24. ISBN 9781845695903.

12. Munim, S.A.; Raza, Z.A. Poly(lactic acid) based hydrogels: Formation, characteristics and biomedical applications. J. Porous Mater. 2019, 26, 881-901. [CrossRef]

13. Vert, M. Aliphatic polyesters: Great degradable polymers that cannot do everything. Biomacromolecules 2005, 6, 538-546. [CrossRef]

14. Seyednejad, H.; Ghassemi, A.H.; Van Nostrum, C.F.; Vermonden, T.; Hennink, W.E. Functional aliphatic polyesters for biomedical and pharmaceutical applications. J. Control. Release 2011, 152, 168-176. [CrossRef]

15. Bilal, M.H.; Hussain, H.; Prehm, M.; Baumeister, U.; Meister, A.; Hause, G.; Busse, K.; Mäder, K.; Kressler, J. Synthesis of poly(glycerol adipate)-g-oleate and its ternary phase diagram with glycerol monooleate and water. Eur. Polym. J. 2017, 91, 162-175. [CrossRef]

16. Albertsson, A.C.; Varma, I.K. Recent developments in ring opening polymerization of lactones for biomedical applications. Biomacromolecules 2003, 4, 1466-1486. [CrossRef]

17. Jiang, Y.; Loos, K. Enzymatic synthesis of biobased polyesters and polyamides. Polymers. 2016, 8, 243. [CrossRef]

18. Naolou, T.; Busse, K.; Kressler, J. Synthesis of well-defined graft copolymers by combination of enzymatic polycondensation and "Click" chemistry. Biomacromolecules 2010, 11, 3660-3667. [CrossRef]

19. Métrai, G.; Wentland, J.; Thomann, Y.; Tiller, J.C. Biodegradable poly(ester hydrazide)s via enzymatic polymerization. Macromol. Rapid Commun. 2005, 26, 1330-1335. [CrossRef]

20. Gross, R.A.; Ganesh, M.; Lu, W. Enzyme-catalysis breathes new life into polyester condensation polymerizations. Trends Biotechnol. 2010, 28, 435-443. [CrossRef] 
21. Naolou, T. Green Route to Prepare Renewable Polyesters from Monomers: Enzymatic Polymerization. In Introduction to Renezwable Biomaterials: First Principles and Concepts; Wiley: Hoboken, NJ, USA, 2017; pp. 219-237. [CrossRef]

22. Kobayashi, S.; Uyama, H.; Kimura, S. Enzymatic polymerization. Chem. Rev. 2001, 101, 3793-3818. [CrossRef]

23. Douka, A.; Vouyiouka, S.; Papaspyridi, L.M.; Papaspyrides, C.D. A review on enzymatic polymerization to produce polycondensation polymers: The case of aliphatic polyesters, polyamides and polyesteramides. Prog. Polym. Sci. 2018, 79, 1-25. [CrossRef]

24. Kobayashi, S. Enzymatic ring-opening polymerization and polycondensation for the green synthesis of polyesters. Polym. Adv. Technol. 2015, 26, 677-686. [CrossRef]

25. Kobayashi, S. Lipase-catalyzed polyester synthesis-A green polymer chemistry. Proc. Jpn. Acad. Ser. B 2010, 86, 338-365. [CrossRef]

26. Kobayashi, S.; Makino, A. Enzymatic polymer synthesis: An opportunity for green polymer chemistry. Chem. Rev. 2009, 109, 5288-5353. [CrossRef]

27. Taresco, V.; Suksiriworapong, J.; Creasey, R.; Burley, J.C.; Mantovani, G.; Alexander, C.; Treacher, K.; Booth, J.; Garnett, M.C. Properties of acyl modified poly(glycerol-adipate) comb-like polymers and their self-assembly into nanoparticles. J. Polym. Sci. Part A Polym. Chem. 2016, 54, 3267-3278. [CrossRef]

28. Orafai, H.; Kallinteri, P.; Garnett, M.; Huggins, S.; Hutcheon, G.; Pourcain, C. Novel poly(glycerol-adipate) polymers used for nanoparticle making: A study of surface free energy. Iran. J. Pharm. Res. 2008, 7, 11-19. [CrossRef]

29. Wersig, T.; Krombholz, R.; Janich, C.; Meister, A.; Kressler, J.; Mäder, K. Indomethacin functionalised poly(glycerol adipate) nanospheres as promising candidates for modified drug release. Eur. J. Pharm. Sci. 2018, 123, 350-361. [CrossRef]

30. Weiss, V.M.; Naolou, T.; Hause, G.; Kuntsche, J.; Kressler, J.; Mäder, K. Poly(glycerol adipate)-fatty acid esters as versatile nanocarriers: From nanocubes over ellipsoids to nanospheres. J. Control. Release 2012, 158, 156-164. [CrossRef]

31. Naolou, T.; Meister, A.; Schöps, R.; Pietzsch, M.; Kressler, J. Synthesis and characterization of graft copolymers able to form polymersomes and worm-like aggregates. Soft Matter 2013, 9, 10364-10372. [CrossRef]

32. Gaskell, E.E.; Hobbs, G.; Rostron, C.; Hutcheon, G.A. Encapsulation and release of $\alpha$-chymotrypsin from poly(glycerol adipateco- $\omega$-pentadecalactone) microparticles. J. Microencapsul. 2008, 25, 187-195. [CrossRef]

33. Abo-zeid, Y.; Mantovani, G.; Irving, W.L.; Garnett, M.C. Synthesis of nucleoside-boronic esters hydrophobic pro-drugs: A possible route to improve hydrophilic nucleoside drug loading into polymer nanoparticles. J. Drug Deliv. Sci. Technol. 2018, 46, 354-364. [CrossRef]

34. Suksiriworapong, J.; Taresco, V.; Ivanov, D.P.; Styliari, I.D.; Sakchaisri, K.; Junyaprasert, V.B.; Garnett, M.C. Synthesis and properties of a biodegradable polymer-drug conjugate: Methotrexate-poly(glycerol adipate). Colloids Surfaces B Biointerfaces 2018, 167, 115-125. [CrossRef]

35. Hu, J.; Gao, W.; Kulshrestha, A.; Gross, R.A. "Sweet polyesters": Lipase-catalyzed condensation-Polymerizations of alditols. Macromolecules 2006, 39, 6789-6792. [CrossRef]

36. Uyama, H.; Kobayashi, S. Enzymatic synthesis of polyesters via polycondensation. In Advances in Polymer Science; Springer: Berlin/Heidelberg, Germany, 2006; Volume 194, pp. 133-158.

37. Nitta, S.; Iwamoto, H. Lipase-catalyzed synthesis of epigallocatechin gallate-based polymer for long-term release of epigallocatechin gallate with antioxidant property. J. Appl. Polym. Sci. 2019, 136, 47693. [CrossRef]

38. Adharis, A.; Loos, K. Synthesis of glycomonomers via biocatalytic methods. In Methods in Enzymology; Elsevier: Amsterdam, The Netherlands, 2019; Volume 627, pp. 215-247. ISBN 9780128170953.

39. Uyama, H.; Wada, S.; Fukui, T.; Kobayashi, S. Lipase-catalyzed synthesis of polyesters from anhydride derivatives involving dehydration. Biochem. Eng. J. 2003, 16, 145-152. [CrossRef]

40. Bilal, M.H.; Prehm, M.; Njau, A.E.; Samiullah, M.H.; Meister, A.; Kressler, J. Enzymatic synthesis and characterization of hydrophilic sugar based polyesters and their modification with stearic acid. Polymers 2016, 8, 80. [CrossRef]

41. Uyama, H.; Inada, K.; Kobayashi, S. Regioselective polymerization of divinyl sebacate and triols using lipase catalyst. Macromol. Rapid Commun. 1999, 20, 171-174. [CrossRef]

42. D'souza, A.A.; Shegokar, R. Polyethylene glycol (PEG): A versatile polymer for pharmaceutical applications. Expert Opin. Drug Deliv. 2016, 13, 1257-1275. [CrossRef] [PubMed]

43. Wunderlich, B. Theory of cold crystallization of high polymers. J. Chem. Phys. 1958, 29, 1395-1404. [CrossRef]

44. Wang, J.; Andriamitantsoa, R.S.; Atinafu, D.G.; Gao, H.; Dong, W.; Wang, G. A one-step in-situ assembly strategy to construct PEG@MOG-100-Fe shape-stabilized composite phase change material with enhanced storage capacity for thermal energy storage. Chem. Phys. Lett. 2018, 695, 99-106. [CrossRef]

45. Pielichowski, K.; Flejtuch, K. Differential scanning calorimetry studies on poly(ethylene glycol) with different molecular weights for thermal energy storage materials. Polym. Adv. Technol. 2002, 13, 690-696. [CrossRef]

46. Kaşgöz, H.; Aydin, I.; Kaşgöz, A. The effect of PEG(400)DA crosslinking agent on swelling behaviour of acrylamide-maleic acid hydrogels. Polym. Bull. 2005, 54, 387-397. [CrossRef]

47. Lange, F.; Schwenke, K.; Kurakazu, M.; Akagi, Y.; Chung, U.I.; Lang, M.; Sommer, J.U.; Sakai, T.; Saalwächter, K. Connectivity and structural defects in model hydrogels: A combined proton NMR and Monte Carlo simulation study. Macromolecules 2011, 44, 9666-9674. [CrossRef]

48. Baum, J.; Pines, A. NMR Studies of Clustering in Solids. J. Am. Chem. Soc. 1986, 108, 7447-7454. [CrossRef] [PubMed] 
49. Saalwächter, K. Proton multiple-quantum NMR for the study of chain dynamics and structural constraints in polymeric soft materials. Prog. Nucl. Magn. Reson. Spectrosc. 2007, 51, 1-35. [CrossRef]

50. Golitsyn, Y.; Pulst, M.; Samiullah, M.H.; Busse, K.; Kressler, J.; Reichert, D. Crystallization in PEG networks: The importance of network topology and chain tilt in crystals. Polymer 2019, 165, 72-82. [CrossRef]

51. Stejskal, E.O.; Tanner, J.E. Spin diffusion measurements: Spin echoes in the presence of a time-dependent field gradient. J. Chem. Phys. 1965, 42, 288-292. [CrossRef]

52. Matsukawa, S.; Ando, I. Study of self-diffusion of molecules in polymer gel by pulsed-gradient spin-echo ${ }^{1} \mathrm{H}$ NMR. Macromolecules 1996, 29, 7136-7140. [CrossRef]

53. Bilal, M.H.; Alaneed, R.; Steiner, J.; Mäder, K.; Pietzsch, M.; Kressler, J. Multiple grafting to enzymatically synthesized polyesters. In Methods in Enzymology; Elsevier: Amsterdam, The Netherlands, 2019; Volume 627, pp. 57-97. ISBN 9780128170953.

54. Lu, C.; Zhong, W. Synthesis of Propargyl-Terminated Heterobifunctional Poly(ethylene glycol). Polymers 2010, 2, 407-417. [CrossRef] 